NATL INST OF STAND \& TECH

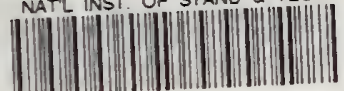

A7li106 977865

NBS

PUBLICATIONS

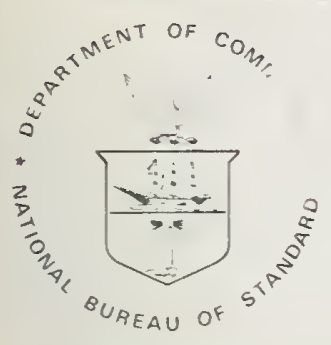

NBS SPECIAL PUBLICATION 400-76

U.S. DEPARTMENT OF COMMERCE/National Bureau of Standards

Semiconductor Measurement Technology:

\title{
TXYZ: A Program for Semiconductor IC Thermal Analysis
}

$+20$

103

.1157

$400-76$

1934 


\section{NATIONAL BUREAU OF STANDARDS}

The National Bureau of Standards' was established by an act of Congress on March 3, 1901. The Bureau's overall goal is to strengthen and advance the Nation's science and technology and facilitate their effective application for public benefit. To this end, the Bureau conducts research and provides: (1) a basis for the Nation's physical measurement system, (2) scientific and technological services for industry and government, (3) a technical basis for equity in trade, and (4) technicai services to promote public safety. The Bureau's technical work is performed by the National Measurement Laboratory, the National Engineering Laboratory, and the Institute for Computer Sciences and Technology.

THE NATIONAL MEASUREMENT LABORATORY provides the national system of physical and chemical and materials measurement; coordinates the system with measurement systems of other nations and furnishes essential services leading to accurate and uniform physical and chemical measurement throughout the Nation's scientific community, industry, and commerce; conducts materials research leading to improved methods of measurement, standards, and data on the properties of materials needed by industry, commerce, educational institutions, and Government; provides advisory and research services to other Government agencies; develops, produces, and distributes Standard Reference Materials; and provides calibration services. The Laboratory consists of the following centers:

\section{Absolute Physical Quantities ${ }^{2}$ - Radiation Research - Chemical Physics - Analytical Chemistry - Materials Science}

THE NATIONAL ENGINEERING LABORATORY provides technology and technical services to the public and private sectors to address national needs and to solve national problems; conducts research in engineering and applied science in support of these efforts; builds and maintains competence in the necessary disciplines required to carry out this research and technical service; develops engineering data and measurement capabilities; provides engineering measurement traceability services; develops test methods and proposes engineering standards and code changes; develops and proposes new engineering practices; and develops and improves mechanisms to transfer results of its research to the ultimate user. The Laboratory consists of the following centers:

Applied Mathematics - Electronics and Electrical Engineering ${ }^{2}$ - Manufacturing Engineering - Building Technology - Fire Research - Chemical Engineering ${ }^{2}$

THE INSTITUTE FOR COMPUTER SCIENCES AND TECHNOLOGY conducts research and provides scientific and technical services to aid Federal agencies in the selection, acquisition, application, and use of computer technology to improve effectiveness and economy in Government operations in accordance with Public Law 89-306 (40 U.S.C. 759), relevant Executive Orders, and other directives; carries out this mission by managing the Federal Information Processing Standards Program, developing Federal ADP standards guidelines, and managing Federal participation in ADP voluntary standardization activities; provides scientific and technological advisory services and assistance to Federal agencies; and provides the technical foundation for computer-related policies of the Federal Government. The Institute consists of the following centers:

Programming Science and Technology-Computer Systems Engineering.

'Headquarters and Laboratories at Gaithersburg, MD, unless otherwise noted; mailing address Washington, DC 20234.

${ }^{2}$ Some divisions within the center are located at Boulder, CO 80303. 
Semiconductor Measurement Technology:

\section{TXYZ: A Program for Semiconductor IC Thermal Analysis}

John Albers

Semiconductor Devices and Circuits Division

Center for Electronics and Electrical Engineering

National Engineering Laboratory

National Bureau of Standards

Washington, DC 20234

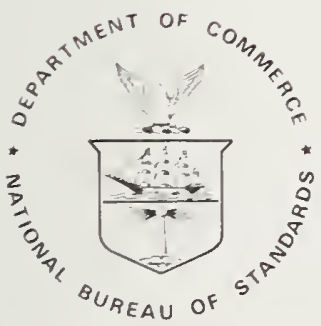

U.S. DEPARTMENT OF COMMERCE, Malcolm Baldrige, Secretary NATIONAL BUREAU OF STANDARDS, Ernest Ambler, Director 
Library of Congress Catalog Card Number: 84-601026

National Bureau of Standards Special Publication 400-76

Natl. Bur. Stand. (U.S.), Spec. Publ. 400-76, 65 pages (Apr. 1984)

CODEN: XNBSAV 
Table of Contents

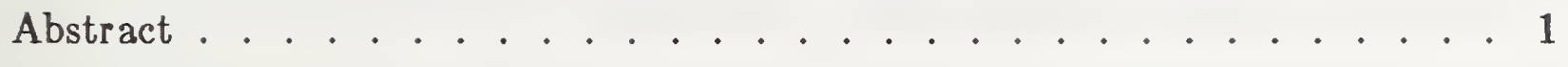

I. Introduction $\ldots \ldots \ldots \ldots$

II. Solution of Steady-State Heat Flow Equation: Single Rectangular Layer 4

III. Solution of Steady-State Heat Flow Equation: Three-Layer Structure . . . 8

IV. Form of the Function $\mathrm{U}(\mathrm{n}, \mathrm{m}) \ldots \ldots \ldots$

V. Behavior of Fourier Coefficients: Small Values of the Argument . . . . 21

VI. Behavior of Fourier Coefficients: Large Values of the Argument . . . . 24

VII. Special Case of Power Source Covering Top Surface . . . . . . . . 30

VIII. Effect of Upper Summation Limits on Temperature Profile . . . . . 32

IX. General Discussion of TXYZ Program . . . . . . . . . . 34

X. Selected Program Examples . . . . . . . . . . . . . . 36

XI. References . . . . . . . . . . . . . . . . . . 38

XII. Appendix A: TXYZ Program Listing _ . . . . . . . . . . . 50 


\section{List of Figures}

Figure 1. This figure presents the geometry of the three-layer structure in which the steady-state temperature is calculated . . . . . . . 39

Figure 2. This figure shows the $n$-dependence of the product of the power density function and the cos terms in eq (92) . . . . . . . . . 40

Figure 3. The top-layer Fourier coefficient, $\tau_{1}(n, m, 0)$, is shown as a function of $n$ and $m$ and at $z=0$ for a three-layer structure where all three layers have different thermal conductivities

Figure 4. The top-layer Fourier coefficient, $\tau_{1}(n, m, 0)$, is shown as a function of $n$ and $m$ and at $z=0$ for a three-layer structure where all three layers have the same thermal conductivity . . . . . . . . . . .

Figure 5. This figure shows the dependence of the three Fourier coefficients on $n$ at the top of each of the layers . . . . . . . . . . . . .

Figure 6. The behavior of the top-layer Fourier coefficient, $\tau_{1}(n, m=$ $0, z=0$ ), along the $n$ axis is presented in this figure . . . . .

Figure 7. This figure shows the calculated temperature as a function of the number of terms used in the sum (eq (98)) for the top of each of the three layers . . . . . . . . . . . . .

Figure 8. This figure presents the calculated temperature along the midline of a 200 mil by 200 mil rectangular structure with a single, uniform power density 1 mil by 1 mil heat source located at the center of the surface of the top layer . . . . . . . . . . . . . .

Figure 9. By way of contrast with the previous figure, the calculated temperature along the midline of a 200 mil by 200 mil three-layer structure is presented in this figure. 
Semiconductor Measurement Technology:

TXYZ: A Program For Semiconductor IC Thermal Analysis

\author{
John Albers \\ Semiconductor Devices and Circuits Division \\ National Bureau of Standards \\ Washington, D.C. 20234
}

\begin{abstract}
A computer program, TXYZ, for the thermal analysis of semiconductor integrated circuits is presented and its applications are discussed. The program makes use of the closed form, analytic solution of the steady-state heat flow problem for a rectangular three-layer structure with multiple heat sources on the top layer. The temperature may be obtained for any point or set of points in the structure and is useful in the determination of the steady-state thermal response of IC chips and packages.
\end{abstract}

Key words: FORTRAN; Fourier analysis; integrated circuit; semiconductor; steadystate heat flow; thermal analysis; thermal resistance. 


\section{INTRODUCTION}

Since the introduction of semiconductor integrated circuits, one of the most important sources of device failure is the lack of temperature control. Hence, an accurate physical picture of the temperature distribution in the device package under the power condition of actual operation is of utmost importance. The purpose of this report is to describe the program, TXYZ, which has been developed for the thermal analysis of integrated circuit packages. In particular, the basic physical model and the mathematical analysis are described and an annotated listing of the program, along with sample data, is presented.

The physical and mathematical model used here is taken in part from work previously carried out by Kokkas [1]. In order to provide the reader with a self-contained document for using TXYZ, much of the development presented by Kokkas has been worked out and specialized to the steady-state heat flow problem. The discussion which follows presents an annotated description of Kokkas' analysis with additional material added where necessary. In particular, the equations have been analyzed in detail so as to investigate the convergence of the solutions used in the numerical implementation. Specifically, the form of the solutions for small and large values of the argument is shown to require special consideration to avoid numerical overflow problems.

This report is naturally broken up into two parts. The first deals with the mathematical and numerical details of the construction of the program. The second deals with the program and its use. For those readers who are interested in the use of the program, the section entitled "GENERAL DISCUSSION OF THE TXYZ 
PROGRAM" begins the portion of the report where the program and specific examples are discussed.

\section{UNITS}

The American semiconductor industry has traditionally used mixed English and metric units, but presently there is a trend in the direction of the International System (SI) units. For the purpose of conversion, it should be noted that 1 mil $=$ $0.001 \mathrm{in} .=25.4 \mu \mathrm{m}$ and that $1 \mathrm{cal} / \mathrm{s}=4.184 \mathrm{~W}$. 


\section{SOLUTION OF STEADY-STATE HEAT FLOW EQUATION:}

\section{SINGLE RECTANGULAR LAYER}

Consider a material of uniform thermal conductivity $\left(\kappa_{1}\right)$, in the form of a rectangular box of lateral dimensions $L_{x}, L_{y}$ and thickness $L_{1}$. The problem is to determine the temperature, $T(x, y, z)$, inside the material. It is assumed that the temperature satisfies the steady-state heat flow equation [2]

$$
\nabla^{2} T(x, y, z)=0
$$

As this equation is second order in the three coordinates, there are six boundary conditions. Four of these will be provided by the lateral boundary conditions. In the present problem, all four of the lateral boundary conditions are provided by the assumption that there is no heat flow out of the lateral boundaries of the material, i.e.,

$$
\left.\frac{\partial T(x, y, z)}{\partial x}\right|_{x=0, L_{x}}=\left.\frac{\partial T(x, y, z)}{\partial y}\right|_{y=0, L_{y}}=0 .
$$

The remaining two boundary conditions will be provided by the vertical boundary conditions (in $z$ ). These vertical boundary conditions will not be specified at the present time as the intent of the present section is to obtain a general solution of the one-layer problem with only the lateral boundary conditions being specified. As the above equation is formulated in Cartesian coordinates, it is convenient to use Fourier analysis techniques to solve the $x$ and $y$ portion of the equation. The Fourier transform with respect to the variables $x$ and $y$ is used, remembering that the geometry is constrained to $0, L_{x}$ and $0, L_{y}$. This is defined as [3] 


$$
\tau\left(f_{x}, f_{y}, z\right)=\int_{0}^{L_{x}} \int_{0}^{L_{y}} T(x, y, z) \exp \left(-2 \pi i\left(x f_{x}+y f_{y}\right)\right) d x d y
$$

where $f_{x}, f_{y}$ are the Fourier transform variables which are conjugate to the variables $x, y$. The inverse Fourier transform is defined as

$$
T(x, y, z)=\int_{-\infty}^{+\infty} \int_{-\infty}^{+\infty} \tau\left(f_{x}, f_{y}, z\right) \exp \left(2 \pi i\left(x f_{x}+y f_{y}\right)\right) d f_{x} d f_{y} .
$$

The requirement that there is no heat flow out of the sides of the structure, i.e., $\partial T(x, y, z) / \partial x$ and $\partial T(x, y, z) / \partial y$ are zero when $x$ and $y$ are either equal to zero or to $L_{x}$ or $L_{y}$, respectively, leads to a consideration of the expression

$$
\frac{\partial T(x, y, z)}{\partial x}=
$$

$$
\int_{-\infty}^{+\infty} \int_{-\infty}^{+\infty} \tau\left(f_{x}, f_{y}, z\right) \exp \left(2 \pi i y f_{y}\right) 2 \pi f_{x}\left\{-\sin \left(2 \pi f_{x} x\right)+i \cos \left(2 \pi f_{x} x\right)\right\} d f_{x} d f_{y}
$$

and a similar expression for $\partial T(x, y, z) / \partial y$. If this is to be zero at the origin, this would require that the cos term be removed. Next, consider the resulting expression at the other lateral boundary, i.e., at $x=L_{x}$ where it is supposed to be zero. The only way that this could be the case is if the argument of the sin function is an integer times $\pi$, or that the Fourier transform variable is of the form

$$
f_{x}=\frac{n}{2 L_{x}}
$$

The same argument applies to the $y$-dependent portion. Then, in the Fourier representation, the temperature (with the above lateral boundary conditions) may be written as

$$
T(x, y, z)=\int_{-\infty}^{+\infty} \int_{-\infty}^{+\infty} \tau(n, m, z) \cos \left(n \pi x / L_{x}\right) \cos \left(m \pi y / L_{y}\right) d f_{x} d f_{y}
$$


The Fourier transform equation is now written as

$$
\tau(n, m, z)=\int_{0}^{L_{x}} \int_{0}^{L_{y}} T(x, y, z) \cos \left(n \pi x / L_{x}\right) \cos \left(m \pi y / L_{y}\right) d x d y .
$$

As the system is of finite size, it is convenient to write the integral in eq (7) as a sum over the Fourier cos terms which fit into the rectangular geometry. Further, as the cos function is symmetric around the origin, the sums may be written over only the non-negative values of the indices. It is important to keep in mind that the terms corresponding to $m, n=0$ do not have the factor of 2 coming from the symmetry of the cos function. In addition, the differentials may be written as

$$
d f_{x}=\Delta \frac{n}{L_{x}}=\frac{n+1}{L_{x}}-\frac{n}{L_{x}}=\frac{1}{L_{x}}
$$

Then, the Fourier representation of the temperature may be written as

$$
T(x, y, z)=\sum_{n=0}^{\infty} \sum_{m=0}^{\infty} \frac{4 \tau(n, m, z) \cos \left(n \pi x / L_{x}\right) \cos \left(m \pi y / L_{y}\right)}{\left(\delta_{n 0}+1\right)\left(\delta_{m 0}+1\right) L_{x} L_{y}}
$$

where $\delta_{n n^{\prime}}$ is the Kronecker delta and is equal to unity if $n=n^{\prime}$ and zero otherwise. By substituting eq (10) into eq (1) and using

$$
\nabla^{2}=\left\{\frac{\partial^{2}}{\partial x^{2}}+\frac{\partial^{2}}{\partial y^{2}}+\frac{\partial^{2}}{\partial z^{2}}\right\}
$$

and

$$
\frac{\partial^{2}}{\partial x^{2}} \cos \left(n \pi x / L_{x}\right)=-\left(n \pi / L_{x}\right)^{2} \cos \left(n \pi x / L_{x}\right),
$$

and the same relation for the $y$-dependence, it is straightforward to show that

$$
\sum_{n=0}^{\infty} \sum_{m=0}^{\infty} \frac{4 \cos \left(n \pi x / L_{x}\right) \cos \left(m \pi y / L_{y}\right)}{\left(\delta_{n}+1\right)\left(\delta_{m}+1\right) L_{x} L_{y}}\left\{-\left(n \pi / L_{x}\right)^{2}-\left(m \pi / L_{y}\right)^{2}+\frac{\partial^{2}}{\partial z^{2}}\right\} \tau(n, m, z)=0 .
$$


As the sum is zero for arbitrary values of the variables $x$ and $y$ (and the cos terms are, in general, nonzero), then a necessary and sufficient condition that eq (13) is satisfied is that

$$
\left\{-\left(n \pi / L_{x}\right)^{2}-\left(m \pi / L_{y}\right)^{2}+\frac{\partial^{2}}{\partial z^{2}}\right\} \tau(n, m, z)=0
$$

This differential equation may be solved analytically using elementary methods. If the variable, $\gamma$, is defined as

$$
\gamma=\left\{\left(\frac{n \pi}{L_{x}}\right)^{2}+\left(\frac{m \pi}{L_{y}}\right)^{2}\right\}^{1 / 2}
$$

then the above equation may be written in the form

$$
\frac{\partial^{2}}{\partial z^{2}} \tau(n, m, z)-\gamma^{2} \tau(n, m, z)=0
$$

The solution of this equation is

$$
\tau(n, m, z)=\alpha \cosh (\gamma z)+\beta \sinh (\gamma z),
$$

where the coefficients $\alpha$ and $\beta$, which may be functions of $\gamma$, are determined from the two $z$-dependent boundary conditions. The above equation is the general solution for the $z$-dependent Fourier expansion coefficients for a single rectangular layer. In the discussion of the problem of a rectangular $j$-layer structure where all of the layers have the same lateral dimensions, the solution in each of the layers can be expressed in the form of the above equation where the coefficients are to be determined from the two $z$-dependent boundary conditions appropriate to each of the layers. This will be used in the next section where the three-layer problem will be discussed. 


\section{SOLUTION OF STEADY-STATE HEAT FLOW EQUATION:}

\section{THREE-LAYER RECTANGULAR STRUCTURE}

The basic problem considered in this section is the calculation of the three-dimensional temperature distribution in a three-layer structure which is assumed to be of the geometric form presented in figure 1 . The three layers are characterized in terms of the thermal conductivities and thicknesses $\kappa_{i}, L_{i}(i=1,2,3)$. One particular example of a three-layer structure is an IC package. For this particular case, the top layer is the semiconductor device, whereas the middle and bottom layers are the die attach and substrate layers. Clearly, the thicknesses and thermal conductivities of these three layers are of considerable importance in the dissipation of heat generated by the power sources on the surface of the semiconductor device. These power sources are typically the regions at or near the surface of the device where currents are passed into the device during normal operation. Consequently, the generation of heat in the device is one of the unavoidable side effects of device operation.

All three layers of the model are assumed to have the same lateral dimensions. This assumption greatly simplifies the analysis in terms of Fourier series which are common to all three layers. In addition, it is assumed that there is no heat flow out of the lateral boundaries of the structure due to either convection or radiation. Again, this makes the analysis more manageable.

The mathematical formulation of this problem is based upon the following set of assumptions:

1) the lateral dimensions of the layers in the structure are all equal while the 
thicknesses may be different,

2) there is no heat loss from the lateral surfaces due to either radiation or convection and heat flow in the structure takes place by conduction,

3) there are no heat losses due to interconnections to the chip (the top layer),

4) there is no thermal contact resistance between the various layers which are in contact,

5) the heat sink, which is in contact with the bottom layer, is ideal and has a temperature equal to ambient,

6) each layer is of uniform, isotropic, temperature-independent thermal conductivity, and

7) there is no input power density inside the structure, heat is generated only on the top surface.

The starting equation for the analysis is the steady-state homogeneous heat flow equation as discussed for the single-layer problem,

$$
\nabla^{2} T(x, y, z)=0 .
$$

In the following discussion, the temperature in the first layer will be referred to as $T_{1}(x, y, z)$, while the temperature in the second and third layers will be denoted by $T_{2}(x, y, z)$ and $T_{3}(x, y, z)$, respectively. Built into the above assumptions is the fact that the temperature and its normal derivative (proportional to the normal heat flow) are continuous at the interfaces between the layers. The assumptions that heat 
enters the structure only on the top surface through the heating elements and that the bottom of the bottom layer is at the same temperature as the heat sink are also available. These provide the six $z$-dependent boundary conditions on the system of equations generated by using the solution of the homogeneous single-layer problem. These boundary conditions may be expressed as follows. First, the assumption that there is no heat flow out of the lateral boundaries is written as

$$
\left.\frac{\partial T_{i}(x, y, z)}{\partial x}\right|_{x=0, L_{x}}=\left.\frac{\partial T_{i}(x, y, z)}{\partial y}\right|_{y=0, L_{v}}=0,(i=1,2,3) .
$$

Next, the assumption that heat enters only where the power is applied in the first layer is expressed as

$$
\left.\kappa_{1} \frac{\partial T_{1}(x, y, z)}{\partial z}\right|_{z=0}=P(x, y)
$$

where $\kappa_{1}$ is the thermal conductivity of the top layer. Further, the assumption that the temperature is continuous across the interfaces between the layers may be written as

$$
\begin{gathered}
\left.T_{1}(x, y, z)\right|_{z=-L_{1}}=\left.T_{2}(x, y, z)\right|_{z=-L_{1}}, \\
\left.T_{2}(x, y, z)\right|_{z=-\left(L_{1}+L_{2}\right)}=\left.T_{3}(x, y, z)\right|_{z=-\left(L_{1}+L_{2}\right)} .
\end{gathered}
$$

The assumption that the heat flow is continuous across the interfaces between the layers is expressed by the conditions that

$$
\begin{aligned}
&\left.\kappa_{1} \frac{\partial T_{1}(x, y, z)}{\partial z}\right|_{z=-L_{1}}=\left.\kappa_{2} \frac{\partial T_{2}(x, y, z)}{\partial z}\right|_{z=-L_{1}}, \\
&\left.\kappa_{2} \frac{\partial T_{2}(x, y, z)}{\partial z}\right|_{z=-\left(L_{1}+L_{2}\right)}=\left.\kappa_{3} \frac{\partial T_{3}(x, y, z)}{\partial z}\right|_{z=-\left(L_{1}+L_{2}\right)} .
\end{aligned}
$$


Finally, the assumption that the temperature is continuous across the interface between the third layer and the heat sink is written as

$$
\left.T_{3}(x, y, z)\right|_{z=-L_{z}}=T_{a}=0,
$$

where all temperatures are measured relative to the ambient heat sink temperature. In the above equations, $\kappa_{i}$ is the thermal conductivity of the $i$-th layer and $L_{z}=$ $L_{1}+L_{2}+L_{3}$. It is also important to note that the origin of the depth scale is at the surface of the top layer and that all vertical distances are negative. For the steady-state situation, the power density may be written as

$$
P(x, y)=U(x, y) P_{0}
$$

where the function $U(x, y)$ is the weighting function which describes the geometry and uniformity (or nonuniformity) of the heat-generating components, and $P_{0}$ is the steady-state power density per unit area. As discussed previously, the ambient temperature trivially satisfies the heat flow equation. Hence, it is convenient to consider all temperatures relative to ambient. Therefore, when the power density is set equal to zero, the temperature will be zero as it is relative to ambient. As the three layers are of the same lateral dimensions and there is no heat flow out of the lateral boundaries, the temperature in each of the three layers may be written in the form of eq (10). Further, the $z$-dependent Fourier expansion coefficients will be of the form of eq (17) and may be written as

$$
\begin{aligned}
& \tau_{1}(n, m, z)=\alpha_{1} \cosh (\gamma z)+\beta_{1} \sinh (\gamma z), \\
& \tau_{2}(n, m, z)=\alpha_{2} \cosh (\gamma z)+\beta_{2} \sinh (\gamma z),
\end{aligned}
$$




$$
\tau_{3}(n, m, z)=\alpha_{3} \cosh (\gamma z)+\beta_{3} \sinh (\gamma z)
$$

There are six unknowns involved in these solutions and they are specifically the set of expansion coefficients $\alpha_{i}, \beta_{i}(i=1,2,3)$. These coefficients may be explicitly evaluated by means of the boundary conditions on the temperature and its derivative evaluated at the interfaces. The Fourier coefficients may be used directly in the above boundary conditions as the temperature is a sum over the Fourier expansion coefficients. By substituting the above equations into the appropriate boundary condition equations, it is possible to obtain a system of six equations in six unknowns. For the present case, this system reduces to one with four equations in four unknowns. The standard method for solving this system is to use Cramer's rule [4] with the Laplace method [4] for the evaluation of the determinants involved. However, instead of using this method explicitly here, the Fourier coefficients for each of the layers will be presented and will be shown to satisfy the heat flow equation and the appropriate boundary conditions. In particular, the Fourier coefficients in the three layers are given by eqs (15-17) in Kokkas' paper. Specializing these to the steady-state situation, these are

$$
\begin{gathered}
\tau_{1}(n, m, z)=A\left\{B \cosh \left(\gamma\left(L_{1}+z\right)\right)+C \sinh \left(\gamma\left(L_{1}+z\right)\right)\right\} \\
\tau_{2}(n, m, z)=A\left\{D \cosh \left(\gamma\left(L_{1}+L_{2}+z\right)\right)+E \sinh \left(\gamma\left(L_{1}+L_{2}+z\right)\right)\right\}, \\
\tau_{3}(n, m, z)=A \sinh \left(\gamma\left(L_{z}+z\right)\right),
\end{gathered}
$$

where

$$
A=\frac{U(n, m) P_{0}}{\kappa_{1} \gamma}\left\{\frac{1}{B \sinh \left(\gamma L_{1}\right)+C \cosh \left(\gamma L_{1}\right)}\right\}
$$




$$
\begin{gathered}
B=D \cosh \left(\gamma L_{2}\right)+E \sinh \left(\gamma L_{2}\right) \\
C=\frac{\kappa_{2}}{\kappa_{1}}\left\{D \sinh \left(\gamma L_{2}\right)+E \cosh \left(\gamma L_{2}\right)\right\} \\
D=\sinh \left(\gamma L_{3}\right) \\
E=\frac{\kappa_{3}}{\kappa_{2}} \cosh \left(\gamma L_{3}\right)
\end{gathered}
$$

and

$$
U(n, m)=\int_{0}^{L_{x}} \int_{0}^{L_{y}} U(x, y) \cos \left(n \pi x / L_{x}\right) \cos \left(m \pi y / L_{y}\right) d x d y
$$

is the double Fourier cos transform of the power density uniformity function. Now, it will be shown that the above are the solutions of the equation (see eq (16))

$$
\frac{\partial^{2}}{\partial z^{2}} \tau_{i}(n, m, z)-\gamma^{2} \tau_{i}(n, m, z)=0
$$

where the subscript $i$ takes on the values of $1,2,3$. This may be easily shown to be the case as

$$
\frac{\partial^{2}}{\partial z^{2}} \cosh (\gamma(L+z))=\gamma^{2} \cosh (\gamma(L+z))
$$

and

$$
\frac{\partial^{2}}{\partial z^{2}} \sinh (\gamma(L+z))=\gamma^{2} \sinh (\gamma(L+z))
$$

where $L$ is a constant and is equal to $L_{1}, L_{1}+L_{2}$, or $L_{z}$ in eqs (30-32). Hence, eqs (30-32) satisfy the $z$-dependent differential equation. Next, it will be shown that these Fourier coefficients satisfy the appropriate boundary conditions. The first of 
these is that

$$
\left.\kappa_{1} \frac{\partial \tau_{1}(n, m, z)}{\partial z}\right|_{z=0}=P(n, m)=U(n, m) P_{0} .
$$

Using the Fourier coefficient given by eq (30) for the top layer, this may be evaluated as

$$
\begin{gathered}
\left.\kappa_{1} \frac{\partial \tau_{1}(n, m, z)}{\partial z}\right|_{z=0}=\kappa_{1} \gamma A\left\{B \sinh \left(\gamma L_{1}\right)+C \cosh \left(\gamma L_{1}\right)\right\} \\
=\kappa_{1} \gamma \frac{U(n, m) P_{0}}{\kappa_{1} \gamma}\left\{\frac{1}{B \sinh \left(\gamma L_{1}\right)+C \cosh \left(\gamma L_{1}\right)}\right\}\left\{B \sinh \left(\gamma L_{1}\right)+C \cosh \left(\gamma L_{1}\right)\right\} \\
=U(n, m) P_{0} .
\end{gathered}
$$

Hence, the top layer boundary condition is satisfied by the $\tau_{1}(n, m, z)$. Next, consider the bottom layer boundary condition, i.e.,

$$
\left.\tau_{3}(n, m, z)\right|_{z=-L_{x}}=0 .
$$

Making use of eq (32), this may be readily evaluated as

$$
\left.\tau_{3}(n, m, z)\right|_{z=-L_{z}}=A \sinh \left(\gamma\left(L_{z}-L_{z}\right)\right)=0 .
$$

Hence, the last boundary condition is satisfied. The final set of boundary conditions to be verified are the ones which pertain to the interface boundary conditions. These are

$$
\begin{gathered}
\left.\tau_{1}(n, m, z)\right|_{z=-L_{1}}=\left.\tau_{2}(n, m, z)\right|_{z=-L_{1}}, \\
\left.\tau_{2}(n, m, z)\right|_{z=-\left(L_{1}+L_{2}\right)}=\left.\tau_{3}(n, m, z)\right|_{z=-\left(L_{1}+L_{2}\right)},
\end{gathered}
$$




$$
\begin{aligned}
\left.\kappa_{1} \frac{\partial \tau_{1}(n, m, z)}{\partial z}\right|_{z=-L_{1}} & =\left.\kappa_{2} \frac{\partial \tau_{2}(n, m, z)}{\partial z}\right|_{z=-L_{1}}{ }^{\prime} \\
\left.\kappa_{2} \frac{\partial \tau_{2}(n, m, z)}{\partial z}\right|_{z=-\left(L_{1}+L_{2}\right)} & =\left.\kappa_{3} \frac{\partial \tau_{3}(n, m, z)}{\partial z}\right|_{z=-\left(L_{1}+L_{2}\right)} .
\end{aligned}
$$

In order to verify these equations, it is simplest to calculate the right- and left-hand sides of the equations and then compare them directly. The left-hand side of the first temperature continuity equation may be evaluated as

$$
\begin{aligned}
\left.\tau_{1}(n, m, z)\right|_{z} & =-L_{1}=A\left\{B \cosh \left(\gamma\left(L_{1}-L_{1}\right)\right)+C \sinh \left(\gamma\left(L_{1}-L_{1}\right)\right)\right\} \\
& =A B=A\left\{D \cosh \left(\gamma L_{2}\right)+E \sinh \left(\gamma L_{2}\right)\right\} .
\end{aligned}
$$

The right-hand side of the equation may be evaluated as

$$
\begin{aligned}
\left.\tau_{2}(n, m, z)\right|_{z=-L_{1}}= & A\left\{D \cosh \left(\gamma\left(L_{1}+L_{2}-L_{1}\right)\right)+E \sinh \left(\gamma\left(L_{1}+L_{2}-L_{1}\right)\right)\right\} \\
& =A\left\{D \cosh \left(\gamma L_{2}\right)+E \sinh \left(\gamma L_{2}\right)\right\} .
\end{aligned}
$$

Hence, the first of the temperature continuity equations satisfies the boundary condition. Next, consider the second temperature continuity equation.

$$
\left.\tau_{2}(n, m, z)\right|_{z=-\left(L_{1}+L_{2}\right)}=\left.\tau_{3}(n, m, z)\right|_{z=-\left(L_{1}+L_{2}\right)},
$$

The left-hand side of the equation may be evaluated as

$$
\begin{gathered}
\left.\tau_{2}(n, m, z)\right|_{z=-\left(L_{1}+L_{2}\right)}=A\left\{D \cosh \left(\gamma\left(L_{1}+L_{2}-L_{1}-L_{2}\right)\right)+E \sinh \left(\gamma\left(L_{1}+L_{2}-L_{1}-L_{2}\right)\right)\right\} \\
=A D=A \sinh \left(\gamma L_{3}\right) .
\end{gathered}
$$


The right-hand side is

$$
\left.\tau_{3}(n, m, z)\right|_{z=-\left(L_{1}+L_{2}\right)}=A \sinh \left(\gamma\left(L_{z}-L_{1}-L_{2}\right)\right)=A \sinh \left(\gamma L_{3}\right) .
$$

Hence, the second temperature continuity equation is satisifed. The next equation to be verified is the first heat flow continuity equation, i.e.,

$$
\left.\kappa_{1} \frac{\partial \tau_{1}(n, m, z)}{\partial z}\right|_{z=-L_{1}}=\left.\kappa_{2} \frac{\partial \tau_{2}(n, m, z)}{\partial z}\right|_{z=-L_{1}}
$$

Evaluating the left-hand side leads to

$$
\begin{gathered}
\left.\kappa_{1} \frac{\partial \tau_{1}(n, m, z)}{\partial z}\right|_{z=-L_{1}}=\kappa_{1} \gamma A\left\{B \sinh \left(\gamma\left(L_{1}-L_{1}\right)\right)+C \cosh \left(\gamma\left(L_{1}-L_{1}\right)\right)\right\} \\
=\kappa_{1} \gamma A C=\kappa_{2} \gamma A\left\{D \sinh \left(\gamma L_{2}\right)+E \cosh \left(\gamma L_{2}\right)\right\} .
\end{gathered}
$$

The right-hand side may be evaluated as

$$
\left.\kappa_{2} \frac{\partial \tau_{2}(n, m, z)}{\partial z}\right|_{z=-L_{1}}=\kappa_{2} \gamma A\left\{D \sinh \left(\gamma L_{2}\right)+E \cosh \left(\gamma L_{2}\right)\right\}
$$

The final equation to be evaluated is that for the heat flow continuity between the second and third layers, i.e.,

$$
\left.\kappa_{2} \frac{\partial \tau_{2}(n, m, z)}{\partial z}\right|_{z=-\left(L_{1}+L_{2}\right)}=\left.\kappa_{3} \frac{\partial \tau_{3}(n, m, z)}{\partial z}\right|_{z=-\left(L_{1}+L_{2}\right)} .
$$

The left-hand side of this equation may be evaluated as

$$
\begin{gathered}
\left.\kappa_{2} \frac{\partial \tau_{2}(n, m, z)}{\partial z}\right|_{z=-\left(L_{1}+L_{2}\right)} \\
=\kappa_{2} \gamma A\left\{D \sinh \left(\gamma\left(L_{1}+L_{2}-L_{1}-L_{2}\right)\right)+E \cosh \left(\gamma\left(L_{1}+L_{2}-L_{1}-L_{2}\right)\right)\right\}
\end{gathered}
$$




$$
=\kappa_{2} \gamma A E=\kappa_{3} \gamma A \cosh \left(\gamma L_{3}\right) .
$$

The right-hand side is

$$
\left.\kappa_{3} \frac{\partial \tau_{3}(n, m, z)}{\partial z}\right|_{z=-\left(L_{1}+L_{2}\right)}=\kappa_{3} \gamma A \cosh \left(\gamma\left(L_{z}-L_{1}-L_{2}\right)=\kappa_{3} \gamma A \cosh \left(\gamma L_{3}\right)\right.
$$

Now that it has been shown that the Fourier coefficients satisfy the steady-state heat flow problem and the appropriate boundary conditions, there are several points to be considered before getting into the body of the program. These include: (1) evaluation of the function $U(n, m)$ for a uniform power source of given size and (2) simplification of the Fourier coefficients for subsequent numerical analysis. The latter point is necessary as the limits of $\gamma$ very small and $\gamma$ very large may give rise to overflow or underflow problems when the program is constructed. 


\section{FORM OF THE FUNCTION U(n,m)}

The first thing to be considered is the form of the function $U(n, m)$ for an arbitrary number of heat sources. This function is defined as

$$
U(n, m)=\int_{0}^{L_{x}} \int_{0}^{L_{y}} U(x, y) \cos \left(n \pi x / L_{x}\right) \cos \left(m \pi y / L_{y}\right) d x d y .
$$

The analysis can most easily be accomplished in terms of a single uniform heat source. The case of an arbitrary number of heat sources follows by summing the results of each heat source. Further, if any of the heat sources are nonuniform, their effects can be constructed by suitably overlapping a number of uniform heat sources. In the coordinate system being used, consider a single heat source denoted by the index $i$ with a corner at the location $\left(x_{i}, y_{i}\right)$ and lengths along the $x$ - and $y$-directions given by $\left(l x_{i}, l y_{i}\right)$. Over the area of the heat source, $U(x, y)$ is assumed to be uniform and equal to unity. Away from the area of the heat source, $U(x, y)$ is assumed to be equal to zero. Then, $U(x, y)$ may be viewed as being a unit step function over the surface of the power source. Consequently, the contribution from this single heat source may be written as

$$
\begin{aligned}
& \int_{0}^{L_{x}} \int_{0}^{L_{y}} U(x, y) \cos \left(n \pi x / L_{x}\right) \cos \left(m \pi y / L_{y}\right) d x d y= \\
& \int_{x_{i}}^{x_{i}+l x_{i}} \int_{y_{i}}^{y_{i}+l y_{i}} \cos \left(n \pi x / L_{x}\right) \cos \left(m \pi y / L_{y}\right) d x d y .
\end{aligned}
$$


The integrals can be simply evaluated to give the result that

$$
\begin{aligned}
U_{i}(n, m) & =\frac{L_{x} L_{y}}{(n \pi)(m \pi)}\left\{\sin \left(\frac{n \pi\left(x_{i}+l x_{i}\right)}{L_{x}}\right)-\sin \left(\frac{n \pi x_{i}}{L_{x}}\right)\right\} \\
& \times\left\{\sin \left(\frac{m \pi\left(y_{i}+l y_{i}\right)}{L_{y}}\right)-\sin \left(\frac{m \pi y_{i}}{L_{y}}\right)\right\} .
\end{aligned}
$$

Similar expressions may be written for each of the heat sources and then summed to give the cumulative heat source effect. In addition, as indicated previously, if there are any nonuniform heat sources, their effect can be constructed by means of overlapping uniform heat sources. Before turning to the small $\gamma$ and large $\gamma$ behavior of the Fourier coefficients, it is important to consider the behavior of the function $U(n, m)$ for either $n=0, m=0$, or both. This is important in the numerical implementation of the solutions as the program will have to calculate the double Fourier cos transform over the range of $n, m$ required by the sum in eq (10). Once the value of $n$ or $m$ is zero, there will be problems with most machines as far as evaluating the seeming divergence. This can be circumvented by investigating the behavior of the function for $n=0$. This may be readily carried out by first noting that the function $U(n, m)$ (for the particular form of $U(x, y)$ ) is a product of two terms. This may be simply written as $U(n, m)=U(n) U(m)$. Then, consider the $n$ (from the $x$ integration) contribution to the function which is given by

$$
U(n)=\frac{L_{x}}{n \pi}\left\{\sin \left(\frac{n \pi\left(x_{i}+l x_{i}\right)}{L_{x}}\right)-\sin \left(\frac{n \pi x_{i}}{L_{x}}\right)\right\}
$$

There is an apparent divergence or infinity if $n$ is simply set equal to zero. This is the way in which a computer would look at the expression. However, this infinity is not real as can be seen by using the expansion of the sin function for small values 
of the argument. In particular,

$$
\sin (x)=x-\frac{x^{3}}{3 !}+\cdots
$$

Making use of this expression for the sin function, it is straightforward to show that

$$
\begin{gathered}
\lim _{n \rightarrow 0} U(n)=\lim _{n \rightarrow 0} \frac{L_{x}}{n \pi}\left\{\sin \left(\frac{n \pi\left(x_{i}+l x_{i}\right)}{L_{x}}\right)-\sin \left(\frac{n \pi x_{i}}{L_{x}}\right)\right\}= \\
\lim _{n \rightarrow 0} \frac{L_{x}}{n \pi}\left\{\left(\frac{n \pi\left(x_{i}+l x_{i}\right)}{L_{x}}\right)-\left(\frac{n \pi x_{i}}{L_{x}}\right)\right\}=l x_{i} .
\end{gathered}
$$

The same conclusion holds for the $y$-dependent portion, i.e., $U(m)$. This must be specially coded to bypass any overflow problem. The specific coding of the heat source may be found in the program listing in the function UZERO.

In general, the function $U(n, m)$ is oscillatory and does not approach zero sufficiently fast for large values of $n$ or $m$. In particular, eq (63) shows that $U_{i}(n, m) \rightarrow 0$ like $1 / n m$ as $m, n \rightarrow \infty$. In addition, the $\cos$ terms in eq (10), i.e., $\cos \left(n \pi x / L_{x}\right)$ $\cos \left(m \pi y / L_{y}\right)$, do not approach a definite limit for large values of the argument. Consequently, the product $U(n, m) \cos \left(n \pi x / L_{x}\right) \cos \left(m \pi y / L_{y}\right)$ tends to zero slowly. An example of the behavior of the $x$-dependent portion of this product function, i.e., $U(n) \cos \left(n \pi x / L_{x}\right)$ is presented in figure 2. The heat source used for this figure is a 1 mil by 1 mil heat source centered on the surface of a 200 mil by 200 mil structure. The product function is evaluated at the midpoint of the heat source. Because of the symmetry used, the function shows damped oscillatory behavior. It is clear from the figure that the product function does not fall off to zero sufficiently fast and hence does not provide for rapid convergence of the calculated temperature using the Fourier representation. 


\section{BEHAVIOR OF FOURIER COEFFICIENTS:}

\section{SMALL VALUES OF THE ARGUMENT}

As has been seen in the treatment of the function $U(n, m)$, care must be taken for the case where both $n$ and $m$ are equal to zero (or $\gamma=0$ ). The same considerations must be carried out for the Fourier coefficients in the three layers. In the solutions in the three layers, the summation indices $n, m$ appear. The summation over these variables is of influence in the variable $\gamma$ according to eq (15). Also, the Fourier coefficients contain the hyperbolic functions which depend upon $\gamma$. For large values of $\gamma$, the sinh and cosh functions grow exponentially. This can present special numerical problems when the summation variables approach the upper limits which may be required for the case of very small heat sources. Hence, special care must be taken to study the behavior of the Fourier coefficients for small $\gamma$ and large $\gamma$ so as to remove any potential numerical overflow problems. Once this is properly taken care of, the Fourier coefficients and the solutions will be numerically well behaved.

First, consider the small $\gamma$ behavior of the Fourier coefficients. This is done by considering the small $\gamma$ behavior of the eqs (30-37) and the small argument behavior of the hyperbolic functions. In the following discussion as well as the discussion of the large $\gamma$ behavior, the term $U(n, m) P_{0} / \kappa_{1}$ will be removed for convenience. This term will henceforth be included explicitly in the sum in eq (10) as the Fourier coefficients for all three layers contain this as a common factor through A (see eqs (30-33)). Then, for small $\gamma$,

$$
E \approx \frac{\kappa_{3}}{\kappa_{2}}
$$




$$
\begin{gathered}
D \approx \gamma L_{3}, \\
C \approx \frac{\kappa_{2}}{\kappa_{1}}\left\{\gamma^{2} L_{2} L_{3}+\frac{\kappa_{3}}{\kappa_{2}}\right\}, \\
B \approx \gamma L_{3}+\frac{\kappa_{3}}{\kappa_{2}} \gamma L_{2},
\end{gathered}
$$

and, remembering that the factor $U(n, m) P_{0} / \kappa_{1}$ has been included explicitly in eq (10),

$$
A \approx \frac{1}{\gamma} \frac{\kappa_{1}}{\kappa_{3}}
$$

Making use of these expressions and the small argument behavior of the hyperbolic functions, it is straightforward to investigate the small $\gamma$ behavior of the solutions. In particular,

$$
\begin{gathered}
\tau_{1}(n, m, z) \approx \frac{1}{\gamma} \frac{\kappa_{1}}{\kappa_{3}}\left\{\gamma L_{3}+\frac{\kappa_{3}}{\kappa_{2}} \gamma L_{2}+\frac{\kappa_{2}}{\kappa_{1}}\left\{\gamma^{2} L_{2} L_{3}+\frac{\kappa_{3}}{\kappa_{2}}\right\} \gamma\left(L_{1}+z\right)\right\} \\
\approx \frac{\kappa_{1}}{\kappa_{3}}\left\{L_{3}+\frac{\kappa_{3}}{\kappa_{2}} L_{2}+\frac{\kappa_{3}}{\kappa_{1}}\left(L_{1}+z\right)\right\} .
\end{gathered}
$$

Then,

$$
\lim _{\gamma \rightarrow 0} \tau_{1}(n, m, z)=\left(L_{1}+z\right)+\frac{\kappa_{1}}{\kappa_{2}} L_{2}+\frac{\kappa_{1}}{\kappa_{3}} L_{3}
$$

Next,

$$
\tau_{2}(n, m, z) \approx \frac{1}{\gamma} \frac{\kappa_{1}}{\kappa_{3}}\left\{\gamma L_{3}+\frac{\kappa_{3}}{\kappa_{2}} \gamma\left(L_{1}+L_{2}+z\right)\right\}
$$

or

$$
\lim _{\gamma \rightarrow 0} \tau_{2}(n, m, z)=\frac{\kappa_{1}}{\kappa_{3}} L_{3}+\frac{\kappa_{1}}{\kappa_{2}}\left(L_{1}+L_{2}+z\right) .
$$


And finally,

$$
\tau_{3}(n, m, z) \approx \frac{1}{\gamma} \frac{\kappa_{1}}{\kappa_{3}}\left\{\gamma\left(L_{1}+L_{2}+L_{3}+z\right)\right\}
$$

or

$$
\lim _{\gamma \rightarrow 0} \tau_{3}(n, m, z)=\frac{\kappa_{1}}{\kappa_{3}}\left(L_{1}+L_{2}+L_{3}+z\right) .
$$

These special forms of the Fourier coefficients (in the limit as $\gamma \rightarrow 0$ ) are necessary in the code to bypass overflow problems for small values of the argument. 


\section{BEHAVIOR OF FOURIER COEFFICIENTS:}

\section{LARGE VALUES OF THE ARGUMENT}

As the Fourier coefficients have been investigated for small $\gamma$ and have been shown to be well behaved when properly written, what remains is to write these coefficients in a form which is amenable for investigating their large $\gamma$ behavior. As noted before, the hyperbolic functions, sinh and $\cosh$, grow exponentially for large values of the argument. On the other hand, the hyperbolic tanh approaches unity for large values of the argument. With this in mind, let us investigate the form of the Fourier coefficients, written as much as possible in terms of the tanh, which takes care of this potential numerical difficulty. To this end, it is convenient to introduce the shorthand notation for the hyperbolic functions, $c(x)=\cosh (x), s(x)=\sinh (x)$, and $t(x)=\tanh (x)$. Making use of this shorthand notation, the Fourier coefficients may be written as

$$
\begin{gathered}
\tau_{1}(n, m, z)=A\left\{B c\left(\gamma\left(L_{1}+z\right)\right)+C s\left(\gamma\left(L_{1}+z\right)\right)\right\} \\
\tau_{2}(n, m, z)=A\left\{D c\left(\gamma\left(L_{1}+L_{2}+z\right)\right)+E s\left(\gamma\left(L_{1}+L_{2}+z\right)\right)\right\} \\
\tau_{3}(n, m, z)=A s\left(\gamma\left(L_{z}+z\right) .\right.
\end{gathered}
$$

where,

$$
\begin{gathered}
A=\frac{1}{\gamma}\left\{\frac{1}{B s\left(\gamma L_{1}\right)+C c\left(\gamma L_{1}\right)}\right\}, \\
B=D c\left(\gamma L_{2}\right)+E s\left(\gamma L_{2}\right),
\end{gathered}
$$




$$
\begin{gathered}
C=\frac{\kappa_{2}}{\kappa_{1}} D_{8}\left(\gamma L_{2}\right)+E c\left(\gamma L_{2}\right), \\
D=s\left(\gamma L_{3}\right) \\
E=\frac{\kappa_{3}}{\kappa_{2}} c\left(\gamma L_{3}\right) .
\end{gathered}
$$

As in the investigation of the small $\gamma$ behavior of the Fourier coefficients, the factor $U(n, m) P_{0} / \kappa_{1}$ has been deleted from eq (78) for convenience. This factor may simply be included in the Fourier representation of the temperature, eq (10), as it is common to all three layers. Now, the above equations (eqs (75-82)) will be rewritten by making use of the definition of the hyperbolic tanh, i.e., $t(x)=s(x) / c(x)$. First, consider the coefficient $C$.

$$
\begin{gathered}
C=\frac{\kappa_{2}}{\kappa_{1}}\left\{D s\left(\gamma L_{2}\right)+E c\left(\gamma L_{2}\right)\right\} \\
C=\frac{\kappa_{2}}{\kappa_{1}}\left\{s\left(\gamma L_{3}\right) g\left(\gamma L_{2}\right)+\frac{\kappa_{3}}{\kappa_{2}} c\left(\gamma L_{3}\right) c\left(\gamma L_{2}\right)\right\} \\
C=\frac{\kappa_{2}}{\kappa_{1}} c\left(\gamma L_{3}\right) c\left(\gamma L_{2}\right)\left\{t\left(\gamma L_{3}\right) t\left(\gamma L_{2}\right)+\frac{\kappa_{3}}{\kappa_{2}}\right\} .
\end{gathered}
$$

Next, the coefficient $B$ may be written as

$$
\begin{gathered}
B=D c\left(\gamma L_{2}\right)+E s\left(\gamma L_{2}\right) \\
B=s\left(\gamma L_{3}\right) c\left(\gamma L_{2}\right)+\frac{\kappa_{3}}{\kappa_{2}} c\left(\gamma L_{3}\right) s\left(\gamma L_{2}\right) \\
B=c\left(\gamma L_{3}\right) c\left(\gamma L_{2}\right)\left\{t\left(\gamma L_{3}\right)+\frac{\kappa_{3}}{\kappa_{2}} t\left(\gamma L_{2}\right)\right\} .
\end{gathered}
$$


Then,

$$
\begin{gathered}
B s\left(\gamma L_{1}\right)+C c\left(\gamma L_{1}\right)= \\
c\left(\gamma L_{3}\right) c\left(\gamma L_{2}\right) s\left(\gamma L_{1}\right)\left\{t\left(\gamma L_{3}\right)+\frac{\kappa_{3}}{\kappa_{2}} t\left(\gamma L_{2}\right)\right\}+c\left(\gamma L_{3}\right) c\left(\gamma L_{2}\right) c\left(\gamma L_{1}\right) \frac{\kappa_{2}}{\kappa_{1}}\left\{t\left(\gamma L_{3}\right) t\left(\gamma L_{2}\right)+\frac{\kappa_{3}}{\kappa_{2}}\right\} \\
=c\left(\gamma L_{3}\right) c\left(\gamma L_{2}\right) c\left(\gamma L_{1}\right)\left\{t\left(\gamma L_{3}\right) t\left(\gamma L_{1}\right)+\frac{\kappa_{3}}{\kappa_{2}} t\left(\gamma L_{1}\right) t\left(\gamma L_{2}\right)+\frac{\kappa_{2}}{\kappa_{1}} t\left(\gamma L_{3}\right) t\left(\gamma L_{2}\right)+\frac{\kappa_{3}}{\kappa_{1}}\right\} .
\end{gathered}
$$

Then, the coefficient $A$ may be written as

$$
A=
$$

$$
\frac{1}{\gamma c\left(\gamma L_{3}\right) c\left(\gamma L_{2}\right) c\left(\gamma L_{1}\right)} \frac{1}{\left\{t\left(\gamma L_{3}\right) t\left(\gamma L_{1}\right)+\frac{\kappa_{3}}{\kappa_{2}} t\left(\gamma L_{1}\right) t\left(\gamma L_{2}\right)+\frac{\kappa_{2}}{\kappa_{1}} t\left(\gamma L_{3}\right) t\left(\gamma L_{2}\right)+\frac{\kappa_{3}}{\kappa_{1}}\right\}}
$$

It is convenient to define the function $\Omega(\gamma)$ as

$$
\Omega(\gamma)=\frac{1}{\left\{t\left(\gamma L_{3}\right) t\left(\gamma L_{1}\right)+\frac{\kappa_{3}}{\kappa_{2}} t\left(\gamma L_{1}\right) t\left(\gamma L_{2}\right)+\frac{\kappa_{2}}{\kappa_{1}} t\left(\gamma L_{3}\right) t\left(\gamma L_{2}\right)+\frac{\kappa_{3}}{\kappa_{1}}\right\}},
$$

which is well behaved for all values of $\gamma$. Then, the coefficient A may be written as

$$
A=\frac{\Omega(\gamma)}{\gamma c\left(\gamma L_{3}\right) c\left(\gamma L_{2}\right) c\left(\gamma L_{1}\right)}
$$


By making use of the above procedure, it is relatively straightforward to show that the Fourier coefficients as given by eqs (75-77) may be written as

$$
\begin{gathered}
\tau_{1}(n, m, z)= \\
\frac{\Omega(\gamma) c\left(\gamma\left(L_{1}+z\right)\right)}{\gamma c\left(\gamma L_{1}\right)}\left\{t\left(\gamma L_{3}\right)+\frac{\kappa_{3}}{\kappa_{2}} t\left(\gamma L_{2}\right)+t\left(\gamma\left(L_{1}+z\right)\right) \frac{\kappa_{2}}{\kappa_{1}}\left(t\left(\gamma L_{3}\right) t\left(\gamma L_{2}\right)+\frac{\kappa_{3}}{\kappa_{2}}\right)\right\}, \\
\tau_{2}(n, m, z)=\frac{\Omega(\gamma) c\left(\gamma\left(L_{1}+L_{2}+z\right)\right)}{\gamma c\left(\gamma L_{1}\right) c\left(\gamma L_{2}\right)}\left\{t\left(\gamma L_{3}\right)+\frac{\kappa_{3}}{\kappa_{2}} t\left(\gamma\left(L_{1}+L_{2}+z\right)\right)\right\},
\end{gathered}
$$

and

$$
\tau_{3}(n, m, z)=\frac{\Omega(\gamma) s\left(\gamma\left(L_{1}+L_{2}+L_{3}+z\right)\right)}{\gamma c\left(\gamma L_{1}\right) c\left(\gamma L_{2}\right) c\left(\gamma L_{3}\right)} .
$$

In eqs (89-91), the function $\Omega(\gamma)$ and the terms inside the curly brackets are well behaved for all values of the variable, $\gamma$. The sinh and cosh terms which remain may still give rise to numerical overflow problems for large values of the argument. However, as both of these functions grow exponentially for large values of the argument and they appear in both the numerator and the denominator of the Fourier coefficients, there will be cancellation. This cancellation for large values of the argument will not be worked out in detail here but is contained in the FORTRAN listing of the program in the function FUNZ. These Fourier coefficients are used in the equation

$$
T_{i}(x, y, z)=P_{0} \sum_{n=0}^{\infty} \sum_{m=0}^{\infty} \frac{4 U(n, m) \tau_{i}(n, m, z) \cos \left(n \pi x / L_{x}\right) \cos \left(m \pi y / L_{y}\right)}{\left(\delta_{n 0}+1\right)\left(\delta_{m 0}+1\right) L_{x} L_{y} \kappa_{1}}
$$

for $i=1,2,3$ to obtain the solutions in each of the three layers. In the above, the term $P_{0} U(n, m) / \kappa_{1}$ has been written out explicitly and is no longer contained in 
the Fourier coefficients. It is important in obtaining the solution in $x, y, z$ to use the appropriate layer equation. This is automatically taken care of in the program as the depth $z$ is compared with the various thicknesses and the corresponding layer Fourier coefficient is used. The user does not have to specify which layer is to be used.

An interesting exercise left to the reader is to show when the three thermal conductivities are equal that the one-layer solution is obtained. Also, another exercise is to show that the one-layer solution is obtained when the thicknesses of the second and third layers are set equal to zero.

In the subsequent discussion, it is important to keep in mind that the Fourier coefficients are functions of the variables $n$ and $m$. As discussed in the previous sections, the power density function $U(n, m)$ tends to zero very slowly for large values of the argument. Also, the cos terms in eq (92) do not tend to any limit as the arguments approach infinity. It is the Fourier coefficients which are responsible for the convergence of the sum. Consequently, some discussion of the $n$ and $m$ behavior of the Fourier coefficients is warranted. To show how the Fourier coefficients behave as a function of $n$ and $m$ (or $\gamma$ ), these functions were studied in some detail. In figure 3 , a three-dimensional plot of the $n$ and $m$ dependence of the top layer Fourier coefficient is shown at $z=0$ for a three-layer structure. In the figure, it can be seen that the Fourier coefficients are peaked at the origin of the $n, m$ plane and approach zero as $n$ and $m$ become large. In addition, figure 4 contains the same type of plot for the situation where all three layers have the same thermal conductivity, i.e., for a thick one-layer structure. 
The dependence on $n$ of the three Fourier coefficients at the top of each layer is contained in figure 5 for the structure used to generate figure 3. The curve marked by $A$ shows the behavior on the top surface of the structure, i. e., at $z=0$. The curves denoted by $B$ and $C$ present the results for the top surfaces of the second and third layers, respectively. Figure 6 is a log-log plot form of figure $5 a$ and is especially important as it shows the slow convergence of the top surface Fourier coefficient which will be discussed in detail in the section on the effects of the upper limit on the calculated temperature. 


\section{SPECIAL CASE OF POWER SOURCE COVERING TOP SURFACE}

As a special case of eq (92), consider the situation of a single power source completely covering the top surface; i.e., there is a single heat source with lateral dimensions equal to that of the three-layer structure. In this particular case, it will be shown that the above equation reduces to the familiar thermal resistance equation. The easiest way to proceed with the analysis is to consider the specific form of the function $U(n, m)$. From eq (63),

$$
U_{1}(n, m)=
$$

$$
\frac{L_{x} L_{y}}{(n \pi)(m \pi)}\left\{\sin \left(\frac{n \pi\left(x_{1}+l x_{1}\right)}{L_{x}}\right)-\sin \left(\frac{n \pi x_{1}}{L_{x}}\right)\right\}\left\{\sin \left(\frac{m \pi\left(y_{1}+l y_{1}\right)}{L_{y}}\right)-\sin \left(\frac{m \pi y_{1}}{L_{y}}\right)\right\} .
$$

For the particular case of uniform surface coverage, $x_{1}=y_{1}=0, l x_{1}=L_{x}$ and $l y_{1}=L_{y}$. Upon substituting these values into the equation, the function reduces to

$$
U_{1}(n, m)=\frac{L_{x} L_{y}}{(n \pi)(m \pi)}\{\sin (n \pi) \sin (m \pi)\}
$$

This is zero when the indices are nonzero. For the case where both of the indices are zero, the use of the expansion of the sin function gives rise to the result that

$$
U_{1}(n, m)=L_{x} L_{y} \delta_{n 0} \delta_{m 0}
$$

If this form of the $U(n, m)$ function is substituted into the equation for the temperature in each of the three layers (eq (92)) and the form of the Fourier expansion coefficients as $\gamma \rightarrow 0$ (eqs (72-74)) is used, it is readily shown that the temperatures 
in the three layers may be written as

$$
\begin{aligned}
& T_{1}(x, y, z)=P_{0}\left\{\frac{L_{1}+z}{\kappa_{1}}+\frac{L_{2}}{\kappa_{2}}+\frac{L_{3}}{\kappa_{3}}\right\} \\
& T_{2}(x, y, z)=P_{0}\left\{\frac{L_{1}+L_{2}+z}{\kappa_{2}}+\frac{L_{3}}{\kappa_{3}}\right\} \\
& T_{3}(x, y, z)=P_{0}\left\{\frac{L_{1}+L_{2}+L_{3}+z}{\kappa_{3}}\right\} .
\end{aligned}
$$

As $P_{0}$ is the power density per unit area, these equations give rise to the usual results of the one-dimensional calculations of the thermal resistance. 


\section{EFFECT OF UPPER SUMMATION LIMITS ON TEMPERATURE}

Previously, the dependence of the Fourier coefficients on $n$ and $m$ has been discussed. Figures 3 to 6 contain typical results of this behavior. The purpose of the present section is to show how this behavior is mirrored in the calculated temperature. In particular, eqs (89-91) will be used in eq (92) with a variable upper summation limit in the latter equation. To simplify the analysis, a single heat source with $y_{i}=0$ and $l y_{i}=L y$ will be used. The width of this stripe heat source will be $l x_{i}=1$ mil. Finally, the lateral dimensions of the three-layer structure will be taken as $L_{x}=L_{y}=200$ mil. This particular choice will require only the $m=0$ term in the sum to be retained while needing a large value of $n$ terms in order to obtain convergence of the sum. As there is complete coverage along the $y$-direction, the $m$-dependent portion of eq (95) may be used in eq (92) to obtain

$$
T_{i}^{N}(x, y, z)=P_{0} \sum_{n=0}^{N} \frac{2 U(n) \tau_{i}(n, 0, z) \cos \left(n \pi x / L_{x}\right)}{\left(\delta_{n 0}+1\right) L_{x} \kappa_{1}}
$$

where the dependence of $T_{i}^{N}(x, y, z)$ on $N$, the upper limit of summation, is considered in this section. Curves A, B, and C in figure 7 show the temperature calculated at the center of the heat source as a function of the number of terms in the sum, $N$, for the top of the first, second, and third layers, respectively. It is clear from the curve in figure 7 a that the calculation of the surface temperature (at $z=0$ ) may require up to at least 350 terms in the sum while, from figures $7 \mathrm{~b}$ and $7 \mathrm{c}$, the temperature below the surface may need only 20 terms to be retained in the sum. From the curve depicted in figure $7 \mathrm{a}$, it may be argued that the number of terms needed to adequately represent a feature size of $\Delta x$ (typical of the lateral size of a heat source) should be on the order of $L_{x} / \Delta x$. For the present case, this ratio 
is about 200. Deeper into the structure, the heat flow has caused the approximate size of the heat current to spread out and hence fewer terms are necessary. This is borne out by the behavior of the temperature in the figure. 


\section{GENERAL DISCUSSION OF THE TXYZ PROGRAM}

The annotated listing of the program is contained in the appendix of this report. In the present section, several aspects of the program will be discussed. The purpose of this discussion is to present the user with information concerning the implementation and/or modification of the program.

The first item is the format in which input data are to be entered. As listed in the program, data are to be entered in a fixed-field format. However, many FORTRAN compilers support free-field or list-directed read statements. Free-field read statements are convenient as they allow the user to change input data without having to be concerned with the tedious process of lining up of the data required by fixed-field read statements. Hence, if the user's FORTRAN compiler allows for free-field read statements, it is strongly suggested that the program be edited such that all read statements are of this form.

The next item is concerned with the situation of the hyperbolic functions being or not being built-in functions. If these functions are contained in the computer's relocatable (or object code) mathematics library, then there are no changes required in the code. If, however, these are not, then it is necessary to write separate function subroutines for the hyperbolic functions. As the hyperbolic functions are easily generated from the exponential function, this is a straightforward process.

Next, it is important to discuss the number of heat sources and the dimension statements used in the program. In its present form, TXYZ will allow up to twenty heat sources. This was deemed sufficient for most problems of interest. However, should the user want to use more than this number of heat sources (especially 
for the case of a number of nonuniform heat sources), it is necessary to change the corresponding dimension statements. This is commented upon in the program and the change is relatively straightforward. The only other comment concerning dimension statements has to do with the number of points at which the temperature is to be calculated and the maximum number of terms to be used in the calculation of the temperature using eq (92). The program allows up to 501 as the maximum number for both of these quantities. This was considered to be adequate for the resolution of the spatial variation of the temperature and for the calculation of the temperature (even for the smallest physically realizable heat source on a structure of typical lateral dimensions). Hence, it is felt that 501 is a good maximum value which gives sufficient detail without excessive use of computer memory space. Should memory allocation be a problem, it may become necessary to reduce these numbers in the dimension statements. It is important to carefully evaluate any reduction in the maximum number of terms in the Fourier representation of the temperature in light of the slow convergence of the surface temperature for small heat sources. Finally, in regard to changing the dimension statements, it is important to change the dimension statements in not only the main program but also in the function subroutines as the dimensioned variables are declared in common and hence must have the same dimensions everywhere (in the main program and the function subroutines) to avoid any register difficulties.

A copy of this FORTRAN program may be obtained from the author by sending a letter of request and a computer tape. 


\section{SELECTED PROGRAM EXAMPLES}

In order to assist the user in the implementation of the TXYZ program, several examples are presented in this section. In particular, the input data files are listed and plots of the temperature profiles are presented in the accompanying figures. The input data files have been annotated in order to facilitate familiarity with the reading of these files. This is especially important because of the number of input variables which set various "switches" inside the program. The corresponding data files will be sent along with the FORTRAN listing of the TXYZ program so as to simplify the implementation of the program and its subsequent use.

Two examples will be discussed in this section. The first is for the situation of a single small heat source on the surface of the top layer. The second example is that of a number of heat sources on the top layer. In particular, one of the heat sources is nonuniform and its construction from uniform heat sources is illustrated in the ccorresponding input data file.

The first example is that of a 1 mil by 1 mil uniform heat source on the surface of a 150 mil by 200 mil three-layer structure. The specific structure is that of 15 mils of silicon on 2 mils of die attach material on 30 mils of a substrate. This threelayer structure will be used in both this example and the one to follow. The input data file for this first example is listed, with annotation, in Table 1. The calculated temperature is presented in figure 8.

The second example is for the same three-layer structure as used in the first example. However, in this case, there are several heat sources, with one of them being nonuniform and built up from uniform heat sources. In particular, there are three 
square uniform heat sources on the right portion of the surface and one uniform heat source in the middle of the surface. The nonuniform heat source is a single rectangular area. The surface temperature calculated along the line $0 \leq x \leq 200$, $y=101$ is presented in figure 9. The input data file is presented in Table 2 .

In addition to these examples, the reader's attention is drawn to the recent review [5] where this program is used in the thermal evaluation of VLSI packages using test chips.

\section{ACKNOWLEDGMENTS}

The author would like to thank Frank F. Oettinger for his continued interest during the course of this work. His relentless use of the program brought many of the early bugs to the surface.

The author would also like to thank Stephen E. Ross who changed the code into a portable FORTRAN form. His assistance in getting the three-dimensional plots is also appreciated. 


\section{REFERENCES}

1. Kokkas, A. G., Thermal Analysis of Multiple-Layer Structures, IEEE Trans. Electron Devices ED-21, 674-681 (1974).

2. Carslaw, H. S., and Jaeger, J. C., Conduction of Heat in Solids, Second Edition (Oxford University Press, 1959).

3. Churchill, R. V., Fourier Series and Boundary Value Problems, Second Edition (McGraw-Hill, 1963).

4. Ayres, F., Jr., Matrices (Schaum Publishing Co., 1950).

5. Oettinger, F. F., Thermal Evaluation of VLSI Packages Using Test Chips - A Critical Review, Solid State Technology 27 (2), 169-179 (1984). 


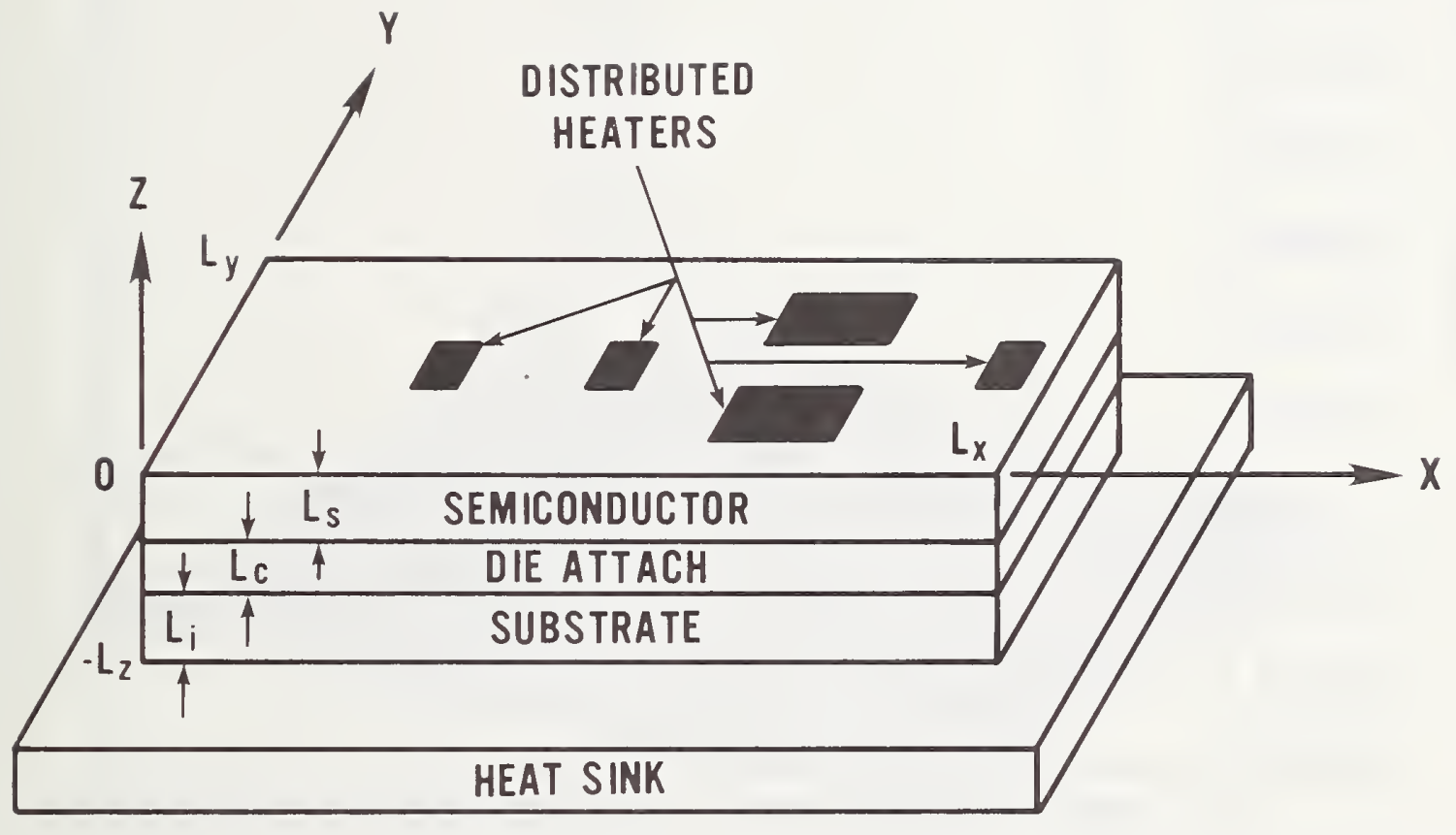

Figure 1. This figure presents the geometry of the three-layer structure in which the steady-state temperature is calculated. 


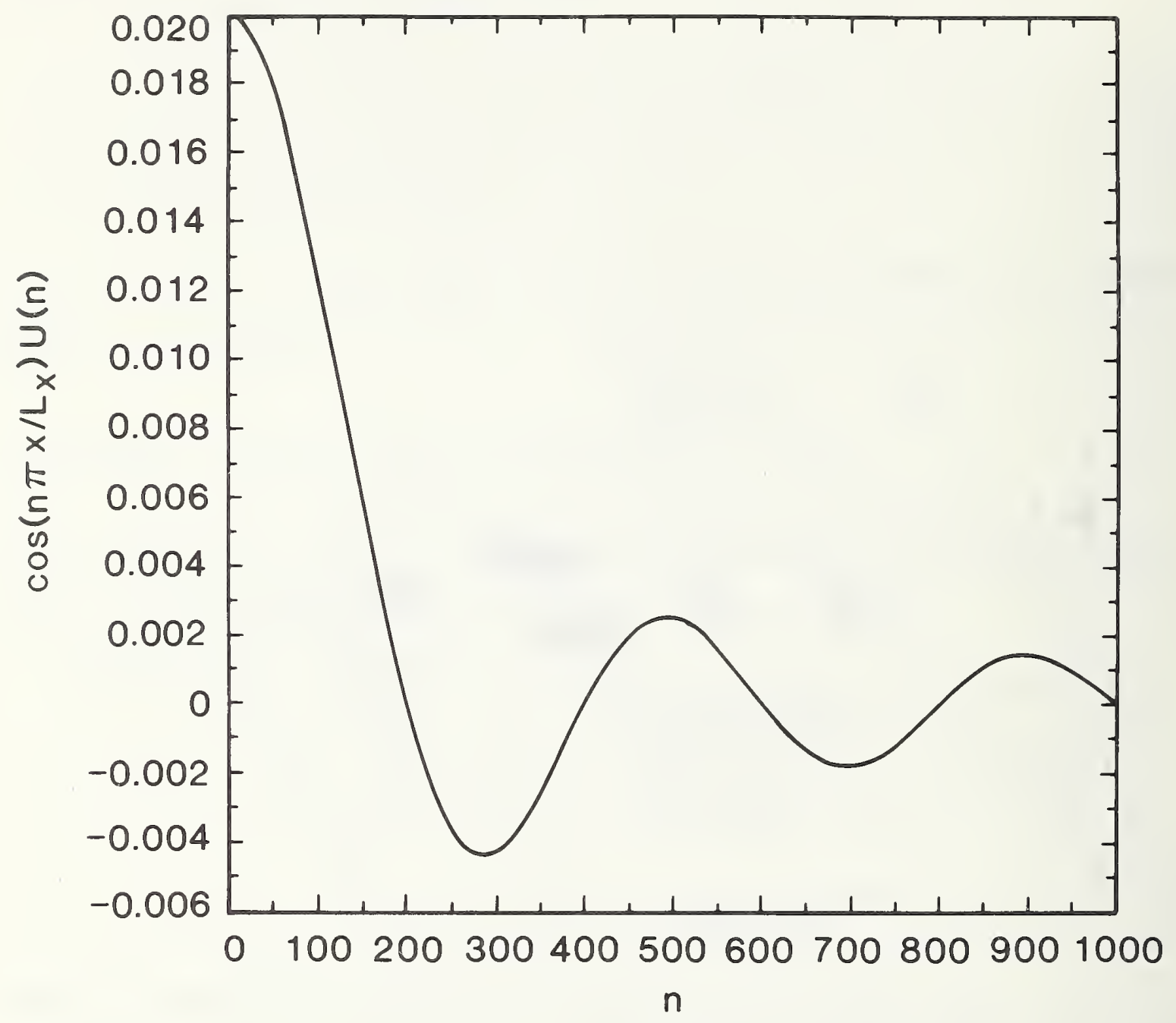

Figure 2. This figure shows the $n$-dependence of the product of the power density function and the cos terms in eq (92), i.e., $U(n) \cos \left(n \pi x / L_{x}\right)$, evaluated at the center of a single small heat source which is in the form of a thin stripe along the $y$ direction. This specific form of the product is used as there is complete coverage along the $y$-direction which means that only the $m=0$ term contributes. The general feature seen in this figure is that this function does not asymptote to zero for $n$ on the order of 500 . This general kind of behavior has been found to be the case for all situations considered. 


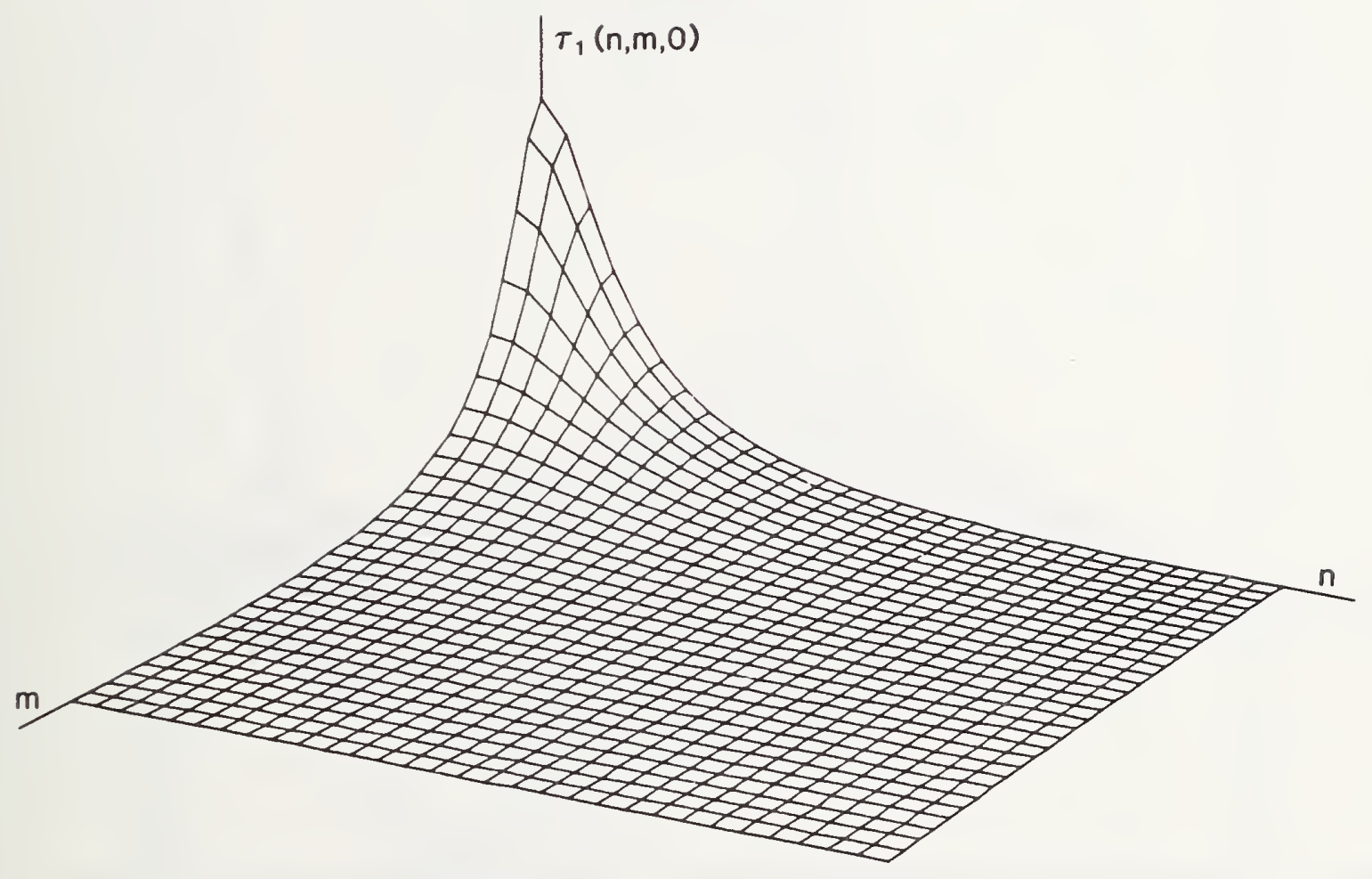

Figure 3. The top-layer Fourier coefficient, $\tau_{1}(n, m, 0)$, is shown as a function of $n$ and $m$ and at $z=0$ for a three-layer structure where all three layers have different thermal conductivities. The specific structure is for 15 mils of silicon $\left(\kappa_{1}=0.00267\right)$ over 2 mils of die attach $\left(\kappa_{2}=0.00064\right)$ over 30 mils of substrate material $\left(\kappa_{3}=\right.$ $0.00999)$. The peak value of $\tau_{1}$ is at the origin of the $n, m$ plane. 


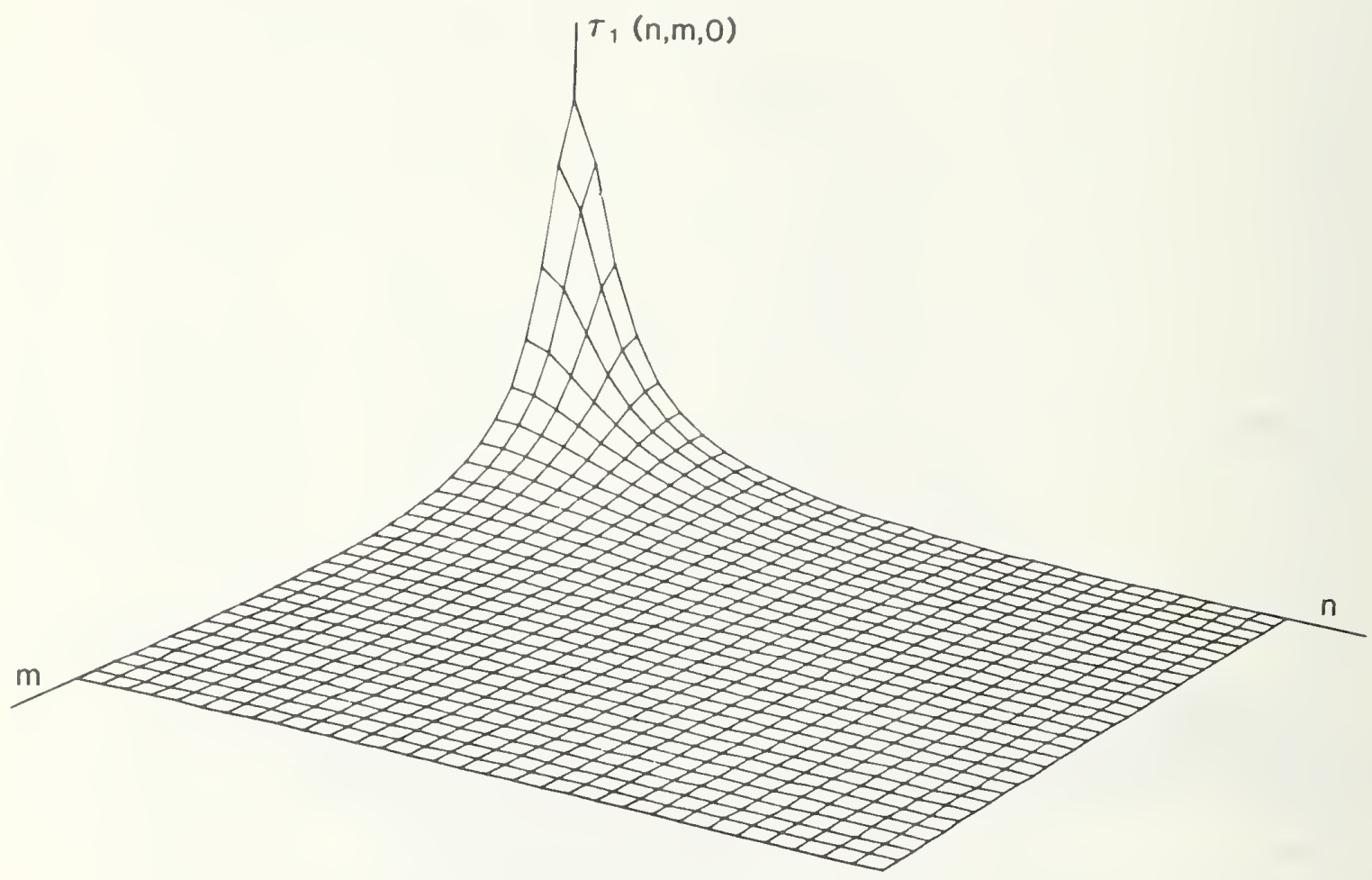

Figure 4. The top-layer Fourier coefficient, $\tau_{1}(n, m, 0)$, is shown as a function of $n$ and $m$ and at $z=0$ for a three-layer structure where all three layers have the same thermal conductivity, i.e., a thick one-layer structure. The specific example is for $\mathbf{4 7}$ mils of silicon $(\kappa=0.00267)$. As with the previous figure, $\tau_{1}$ is peaked at the origin of the $n, m$ plane. Both this and the previous figure are meant to convey qualitative features of the Fourier coefficient. More detailed information will be presented in the next two figures where specific attention will be focused upon just the $n$ axis (with $m=0$ ) behavior. 


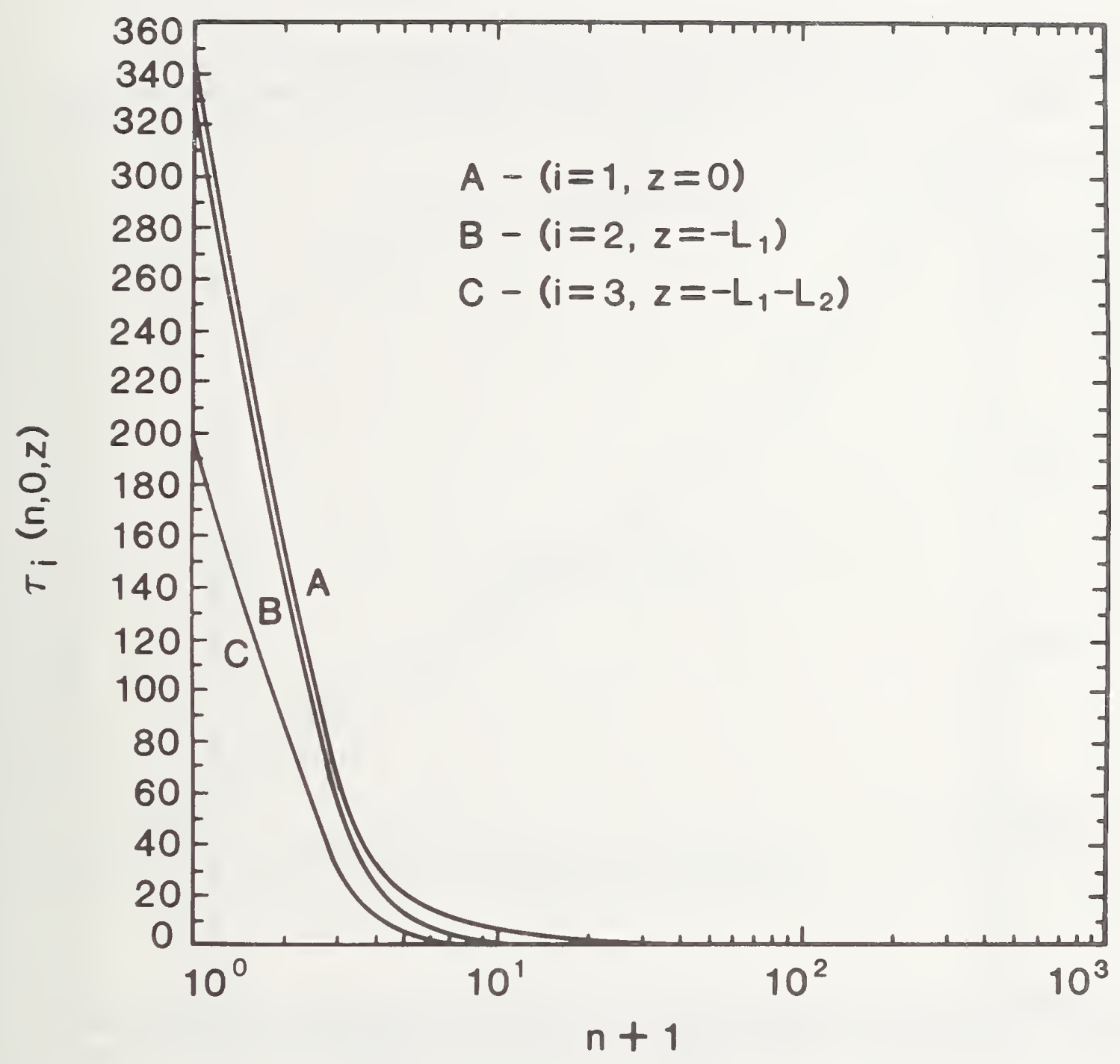

Figure 5. This figure shows the dependence of the three Fourier coefficients on $n$ at the top of each of the layers. The curve denoted by $\mathrm{A}$ is $\tau_{1}(n, m=0, z=0)$ (for the top of the first layer). B shows the Fourier coefficient, $\tau_{2}\left(n, m=0, z=-L_{1}\right)$ (for the top of the second layer). Finally, the curve denoted by $\mathrm{C}$ represents the Fourier coefficient, $\tau_{3}\left(n, m=0, z=-L_{1}-L_{2}\right)$, i.e., at the top of the third layer. This figure and the next represent a cross section along the $n$ axis of figures of the type presented in figures 3 and 4. 


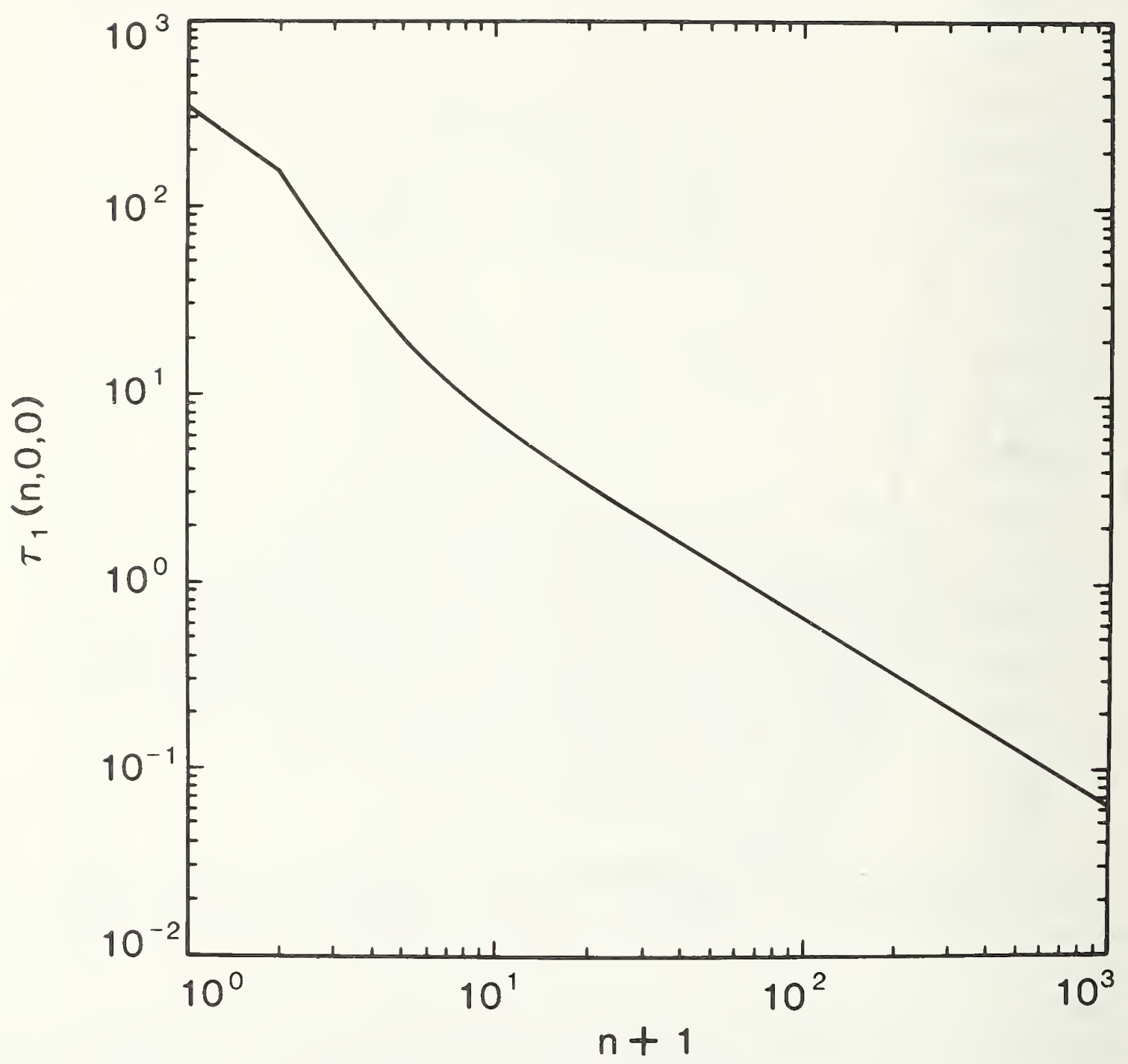

Figure 6. The behavior of the top layer Fourier coefficient, $\tau_{1}(n, m=0, z=0)$, along the $n$ axis is presented in this figure. These results (curve $\mathrm{A}$ of fig. 5) are presented in a log-log plot to show the slow convergence at $z=0$. When curves $\mathrm{B}$ and $\mathrm{C}$ of figure 5 are plotted in the same manner, they fall off to zero much more rapidly. 


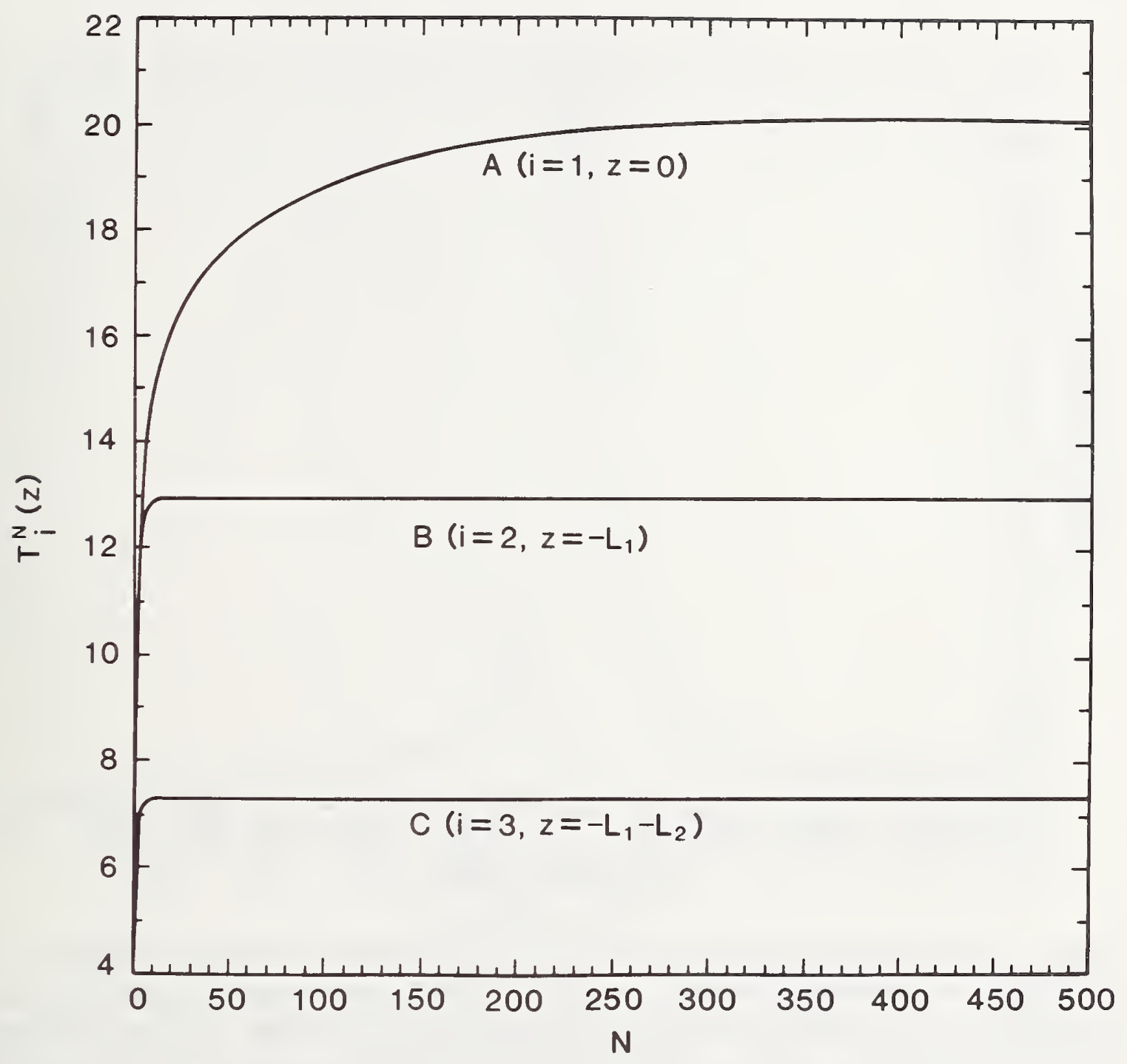

Figure 7. This figure shows the calculated temperature as a function of the number of terms used in the sum (eq (98)) for the top of each of the three layers. Curve $A$ is $T_{1}^{N}(z=0)$ while curves B and C represent $T_{2}^{N}\left(z=-L_{1}\right)$ and $T_{3}^{N}\left(z=-L_{1}-L_{2}\right)$, respectively. This figure clearly shows how the behavior of the Fourier coefficients for each of the layers is mirrored in the corresponding calculated temperatures. 


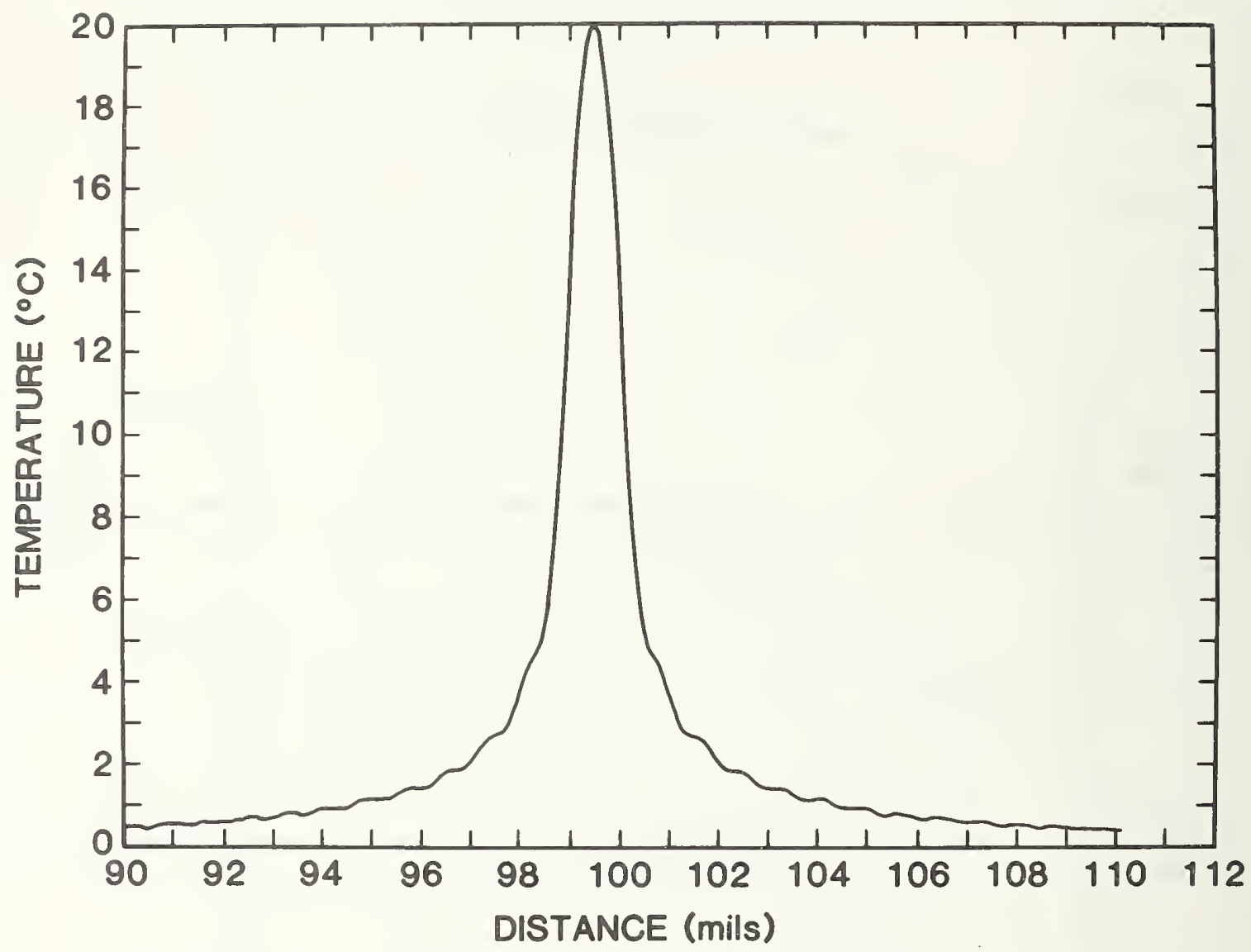

Figure 8. This figure presents the calculated temperature along the midline of a 200 mil by 200 mil rectangular structure with a single, uniform power density 1 mil by 1 mil heat source located at the center of the surface of the top layer. Note that only the temperature in the region of the heat source is plotted, i.e., from 90 mils to 110 mils. Also, note that the temperature falls off rapidly away from the heat source. The specific structure is that of 15 mils of silicon on 2 mils of die attach material on 30 mils of substrate material. The annotated input data file used to obtain this temperature data is to be found in Table I. 


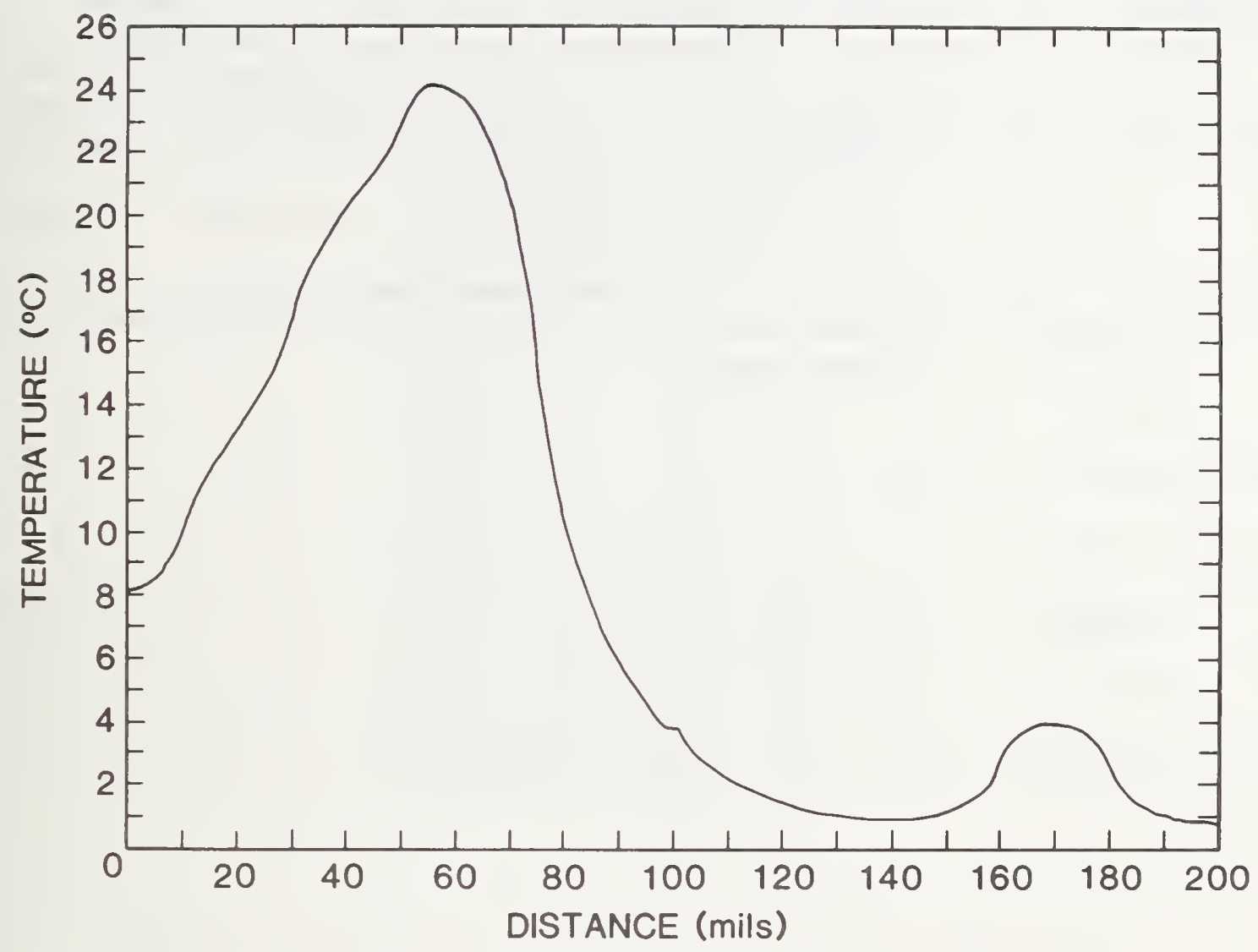

Figure 9. By way of contrast with the previous figure, the calculated temperature along the midline of a 200 mil by 200 mil three-layer structure is presented in this figure. However, in this case, two nonuniform heat sources and one uniform heat source are used. The three-layer structure is the same as used in the previous figure. The construction of the nonuniform heat sources from a number of uniform heat sources is contained in the annotated input data file contained in Table II. 


\section{TABLE I}

INPUT DATA FOR SINGLE HEAT SOURCE

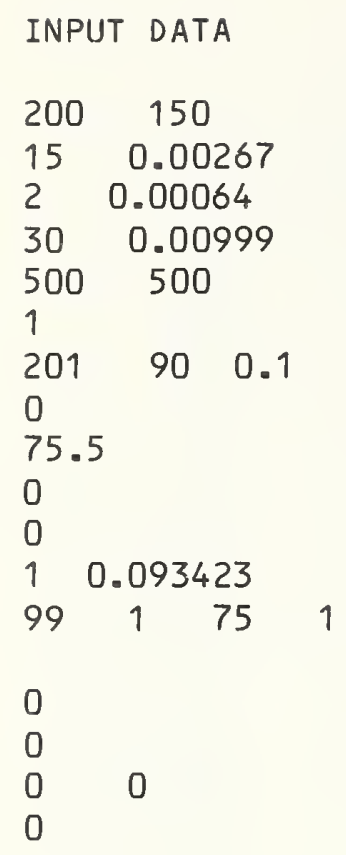

DESCRIPTION OF INPUT DATA

$X$ AND $Y$ DIMENSIONS OF RECTANGULAR STRUCTURE

THICKNESS AND THERMAL CONDUCTIVITY OF TOP LAYER

THICKNESS AND THERMAL CONDUCTIVITY OF MIDDLE LAYER

THICKNESS AND THERMAL CONDUCTIVITY OF BOTTOM LAYER UPPER SUMMATION LIMITS FOR $N$ AND M SUMMATIONS

IEDGEX ( $=0$ FOR SINGLE POINT, =1 FOR NUMBER OF POINTS)

NUMBER OF POINTS ALONG $X$, FIRST POINT, STEP INCREMENT

IEDGEY ( $=0$ FOR SINGLE POINT, $=1$ FOR NUMBER OF POINTS $)$

Y POINT FOR CALCULATION

IEDGEZ ( $=0$ FOR SINGLE POINT, $=1$ FOR NUMBER OF POINTS)

$Z$ POINT FOR CALCULATION

NUMBER OF HEAT SOURCES AND POWER DENSITY

$X$ COORDINATE, LENGTH ALONG $X$ AXIS, Y COORDINATE, LENGTH ALONG Y AXIS 
TABLE II

INPUT DATA FOR MULTIPLE, NONUNIFORM HEAT SOURCES

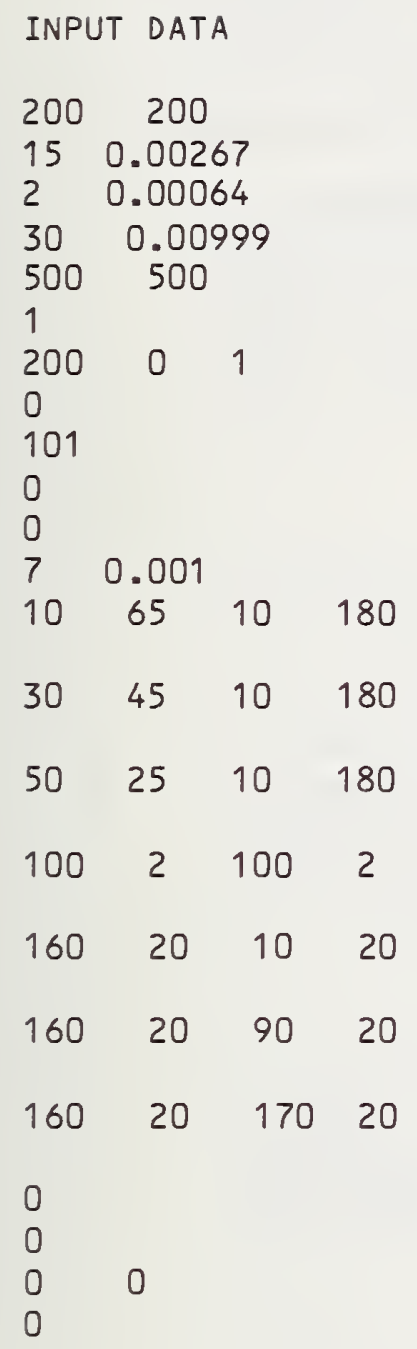

DESCRIPTION OF INPUT DATA

$X$ AND $Y$ DIMENSIONS OF RECTANGULAR STRUCTURE

THICKNESS AND THERMAL CONDUCTIVITY OF TOP LAYER

THICKNESS AND THERMAL CONDUCTIVITY OF MIDDLE LAYER

THICKNESS AND THERMAL CONDUCTIVITY OF BOTTOM LAYER UPPER SUMMATION LIMITS FOR $N$ AND M SUMMATIONS

IEDGEX ( $=0$ FOR SINGLE POINT, $=1$ FOR NUMBER OF POINTS $)$

NUMBER OF POINTS ALONG $X$, FIRST POINT, STEP INCREMENT

IEDGEY ( $=0$ FOR SINGLE POINT, $=1$ FOR NUMBER OF POINTS)

$Y$ POINT FOR CALCULATION

IEDGEZ ( $=0$ FOR SINGLE POINT, $=1$ FOR NUMBER OF POINTS)

$Z$ POINT FOR CALCULATION

NUMBER OF HEAT SOURCES AND POWER DENSITY

$X$ COORDINATE, LENGTH ALONG $X$ AXIS, $Y$ COORDINATE, LENGTH

ALONG $Y$ AXIS FOR HEATER \#1

$X$ COORDINATE, LENGTH ALONG $X$ AXIS, $Y$ COORDINATE, LENGTH ALONG $Y$ AXIS FOR HEATER \#2

$X$ COORDINATE, LENGTH ALONG $X$ AXIS, $Y$ COORDINATE, LENGTH ALONG Y AXIS FOR HEATER \#3

$X$ COORDINATE, LENGTH ALONG $X$ AXIS, $Y$ COORDINATE, LENGTH ALONG Y AXIS FOR HEATER \#4

$X$ COORDINATE, LENGTH ALONG $X$ AXIS, $Y$ COORDINATE, LENGTH ALONG $Y$ AXIS FOR HEATER \#5

$X$ COORDINATE, LENGTH ALONG $X$ AXIS, $Y$ COORDINATE, LENGTH ALONG Y AXIS FOR HEATER \#6

$X$ COORDINATE, LENGTH ALONG $X$ AXIS, $Y$ COORDINATE, LENGTH ALONG Y AXIS FOR HEATER $\# 7$ 
YSOUR (1) ( $Y$ COORDINATE OF ORIGIN OF 1ST SOURCE)

RLXSOUR(1) (LENGTH ALONG X DIRECTION OF 1ST SOURCE)

RLYSOUR(1) (LENGTH ALONG Y DIRECTION OF 1ST SOURCE)

REMAINING HEAT SOURCES WITH SAME INPUT STRUCTURE AS

C

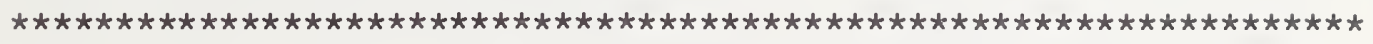

DIMENS ION $X(501), Y(501), Z(501), \operatorname{COSYT}(501)$

DIMENSION ARUZER $(501,501)$, ARFUNZ $(501,501)$

DIMENSION XSOUR (20), YSOUR (20), RLXSOR (20), RLYSOR(20)

COMMON RKS, RKC, RKI, RLX, RLY, RLS, RLC, RLI

COMMON NSOUR, XSOUR, YSOUR, RLXSOR, RLYSOR

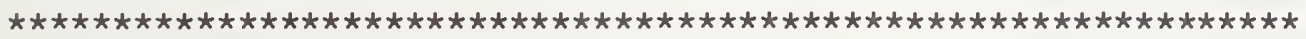

DOCUMENTATION AND BACKGROUND

THIS PROGRAM CALCULATES THE SURFACE TEMPERATURE $T(X, Y, Z)$ DUE TO DC POWER INPUTS ONLY. THE TEMPERATURE IS THE TEMPERATURE RELATIVE TO THE AMBIENT. THE SPECIFIC EQUATIONS USED ARE GIVEN IN EQUATIONS (13)-(23), WITH S=0 (STEADY-STATE CONDITION), IN THE PAPER BY KOKKAS (REF: "THERMAL ANALYSIS OF MULTIPLELAYERED STRUCTURES" BY ACHILLES G. KOKKAS, IEEE TRANS. ELEC. DEV. VOL. ED-21, NO. 11, 674-681 (1974)).

VARIABLES USED: THE VARIABLES LISTED AS REAL IN THE ABOVE ARE THE FOLLOWING-KS,KC, AND KI ARE THE THERMAL CONDUCTIVITIES OF THE SEMICONDUCTOR, CONDUCTOR, AND INSULATOR, RESPECTIVELY. LX AND LY ARE THE LATERAL DIMENSION OF THE CHIP WHILE LS,LC, AND LI ARE THE THICKNESSES OF THE SEMICONDUCTOR, THE CONDUCTOR, AND THE INSULATOR, RESPECTIVELY.

IMPORTANT NOTE: WHILE THE VARIABLES HAVE THE NOTATION WHICH SEEMS TO IMPLY A SEMICONDUCTOR, A CONDUCTOR, AND AN INSULATOR, THESE REFER TO THE WAY IN WHICH KOKKAS FORMULATED THE PROBLEM. THE THING TO KEEP IN MIND IS THAT THE TOP LAYER HAS (LS,KS), THE MIDDLE LAYER HAS (LC,KC), AND THE BOTTOM LAYER HAS (LI,KI). IT IS NOT NECESSARY THAT THEY BE WHAT THEY SEEM TO BE, THEY ARE DETERMINED BY THE RESPECTIVE THICKNESSES, L, AND CONDUCTIVITIES,K.

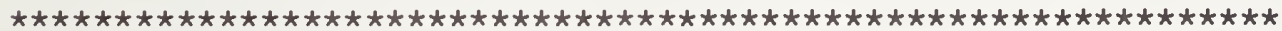

FORMAT (1H1)

FORMAT( $1 X$, 'STEADY-STATE THERMAL ANALYSIS CALCULATION USING EQS.

1 (13)-(23) OF KOKKAS' $/$ )

FORMAT( $1 X$, 'THERMAL CONDUCTIVITIES AND LAYER THICKNESSES')

FORMAT (1X,'KS= ',F10.8,' $K C=$ ',F10.8,' $K I=1, F 10.8)$

FORMAT(1X,'LS= ',F10.5,' LC= ',F10.5,' LI= ',F10.5)

FORMAT( $/ 1 X$, 'UPPER SUMMATION LIMITS ', $2 X, 1$ NUP=', I5,

1 ' MUP $=$ ', I5/)

FORMAT $(/ / 1 \mathrm{X}$, 'NUMBER OF HEAT SOURCES $=1$, I5)

FORMAT ( $/ 1 X$, ' COORDINATES, LENGTHS, AND WIDTHS OF HEAT SOURCES' $/$ )

FORMAT ( $1 X$, 'HEAT SOURCE ',7X,'XSOUR', 10X,'YSOUR', 9X, 'LXSOUR',

$19 X$, 'LYSOUR' /)

FORMAT $(7 X, I 3,5 X, F 10.5,5 X, F 10.5,5 X, F 10.5,5 X, F 10.5)$ 
C

C

C

C C

C RLX AND RLY ARE THE $X$ AND $Y$ DIMENSIONS OF THE RECTANGULAR STRUCTURE

FORMAT $(1 X$, 'POWER DENSITY=', F12.6)

FORMAT( $/ 1 X,{ }^{\prime}$ CALCULATING ', I3, $X$ POINTS WITH A FIRST POINT OF ' $1, F 5.1, \circ$ AND A STEP SIZE OF ',F5.1)

FORMAT $(11 \mathrm{X}$, 'THE CONSTANT $X$ COORDINATE IS ',F5.1)

FORMAT $(/ 1 X, '$ CALCULATING ', I3,' $Y$ POINTS WITH A FIRST POINT OF ' $1, F 5.1, \circ$ AND A STEP SIZE OF ',F5.1)

FORMAT $(/ 1 X, 1$ THE CONSTANT $Y$ COORDINATE IS ',F5.1)

FORMAT( $/ 1 X, ' C A L C U L A T I N G$ ',I3,' $Z$ POINTS WITH A FIRST POINT OF ' $1, F 5.1,1$ AND A STEP SIZE OF ',F5.1)

FORMAT( $/ 1 X$, 'THE CONSTANT $Z$ COORDINATE IS ', F5.1)

FORMAT $\left(1 X,{ }^{\prime} L X=', F 7.2,3 X,{ }^{\prime} L Y=', F 7.2\right)$

FORMAT $(1 X, 3 F 8.2, F 10.4)$

FORMAT $(1 X, 6 I 7)$

FORMAT $(I 4,3 X, I 4)$

FORMAT (F10.5,3X,F10.5)

FORMAT ( I 1)

FORMAT (I 4, 3X, F10.5, 3X, F10.5)

FORMAT (F10.5)

FORMAT (I2, 3X, F10.5)

FORMAT (F10.5, 3X, F10.5,3X,F10.5,3X,F10.5)

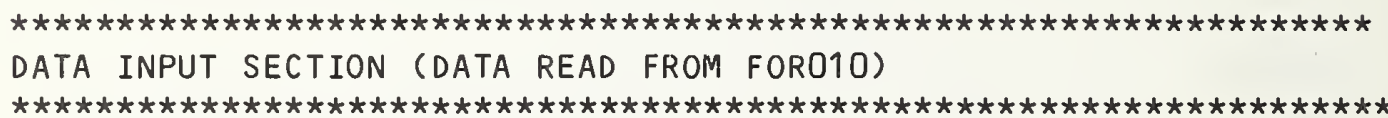

IXFLG $=0$

IYFLG $=0$

$I Z F L G=0$

ILX $=0$

$I L Y=0$

$I L Z=0$

STEPX $=1.0$

STEPY $=1.0$

STEPZ $=-1.0$

WRITE $(11,1)$

WRITE $(11,2)$

WRITE $(11,3)$ $\operatorname{READ}(10,52) \mathrm{RLX}, \mathrm{RLY}$ WRITE $(11,27) R L X, R L Y$

RLS IS THE THICKNESS AND RKS IS THE THERMAL CONDUCTIVITY OF THE TOP LAYER READ $(10,52)$ RLS, RKS

RLC IS THE THICKNESS AND RKC IS THE THERMAL CONDUCTIVITY THE MIDDLE LAYER READ $(10,52)$ RLC, RKC

C RLI IS THE THICKNESS AND RKI IS THE THERMAL CONDUCTIVITY THE BOTTOM LAYER READ $(10,52)$ RLI, RKI WRITE $(11,5)$ RLS, RLC, RLI WRITE $(11,4)$ RKS, RKC, RK I

NUP IS THE UPPER LIMIT OF THE SUMMATION OVER THE INDEX $N$ (X-DIR)

MUP IS THE UPPER LIMIT OF THE SUMMATION OVER THE INDEX M ( $Y$-DIR)

READ $(10,51)$ NUP, MUP

WR ITE $(11,6)$ NUP, MUP 


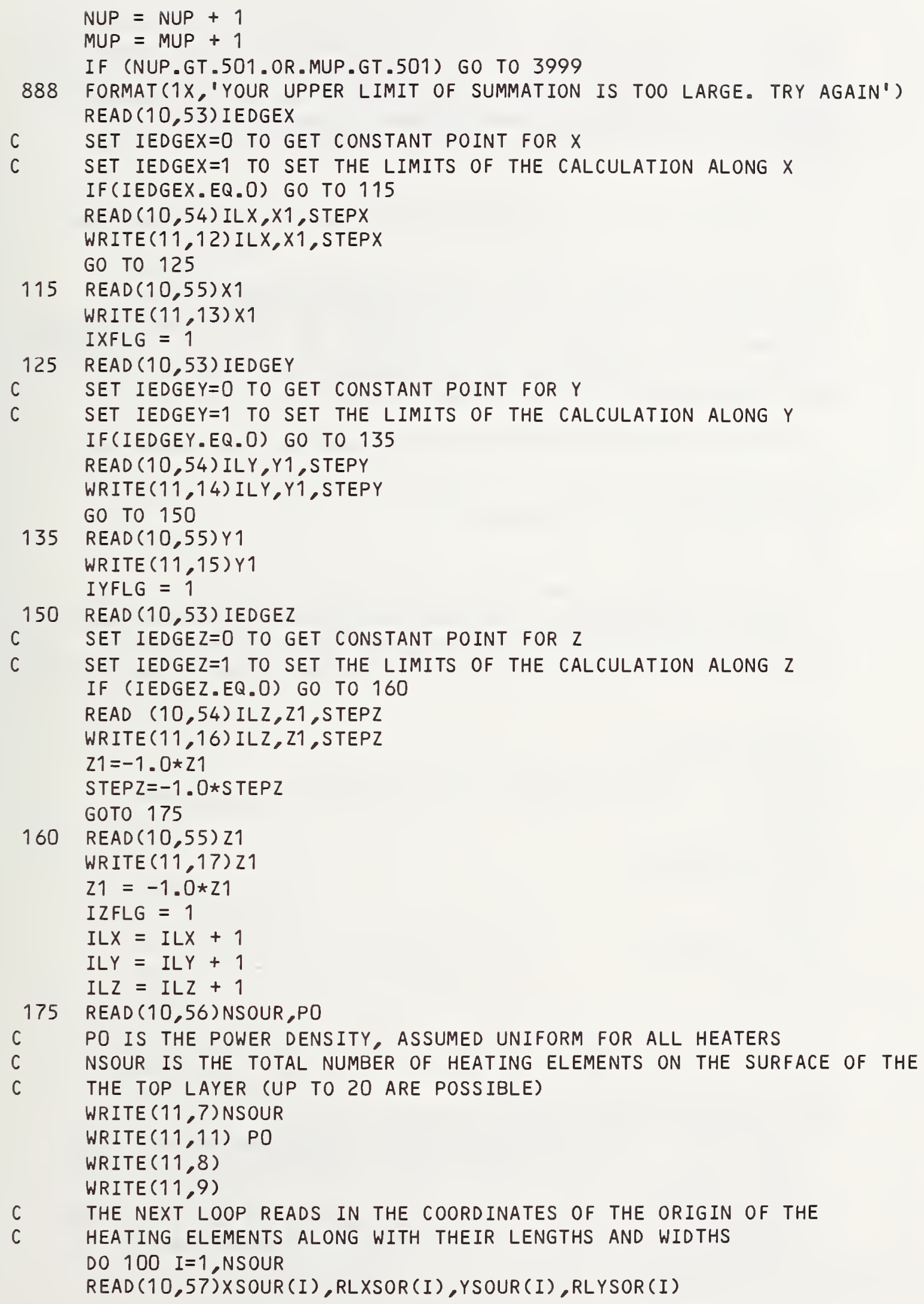


C XSOUR(I) IS THE $X$ COORDINATE OF THE ORIGIN OF I-TH HEATER ELEMENT C RLXSOR(I) IS THE LENGTH OF THE I-TH HEATER ALONG THE X DIRECTION C YSOUR(I) IS THE Y COORDINATE OF THE ORIGIN OF I-TH HEATER ELEMENT C RLYSOR(I) IS THE LENGTH OF THE I-TH HEATER ALONG THE Y DIRECTION

$c$
$C$
$C$
$C$
$C$
$C$
$C$
$C$
$C$
$C$
$C$
$C$ WRITE $(11,1)$

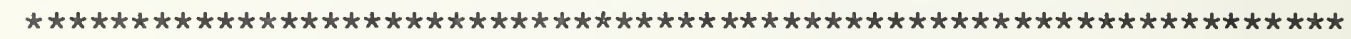

END OF DATA INPUT SECTION

END OF INPUT SECTION. THE THERMAL CONDUCTIVITIES OF THE

$180 \mathrm{PI}=3.14159265$

$P 04 L K=4.0 * P 0 /(R L X * R L Y * R K S)$

$P I L X=P I / R L X$

$P I L Y=P I / R L Y$

C

C

$\mathrm{C}$

C

C

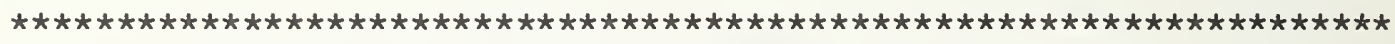
FUNCTION, $U(X, Y)$, THE POWER DENSITY FUNCTION FOR ALL OF THE HEAT SOURCES.

2) $\operatorname{FUNZ}(N, M, Z)$ - CALCULATES THE Z-DEPENDENT PORTION OF THE SUM REMEMBERING THAT THIS IS A FUNCTION OF THE SUMMATION INDICES $(N, M)$. 


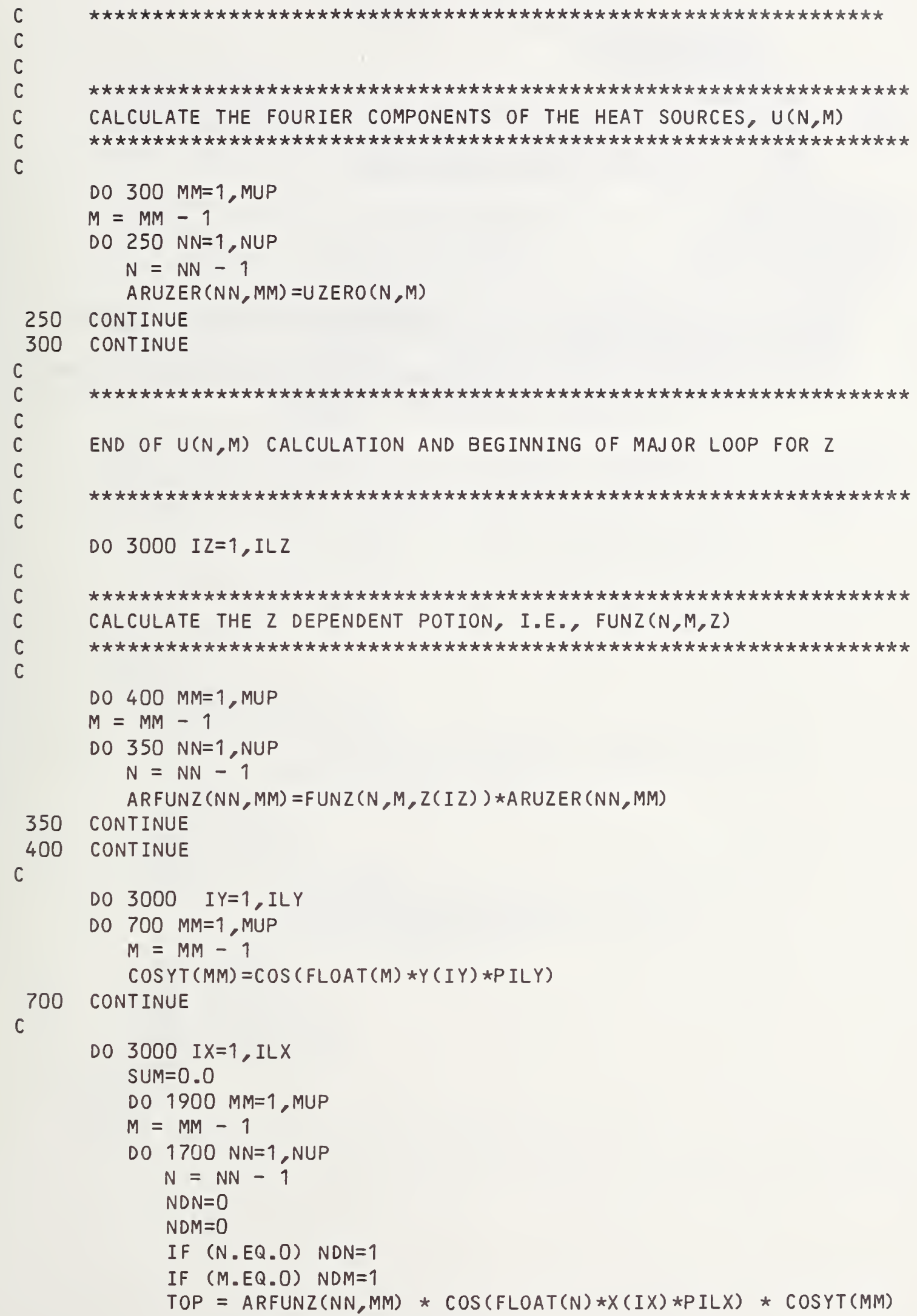




\section{APPENDIX A--TXYZ PROGRAM LISTING}

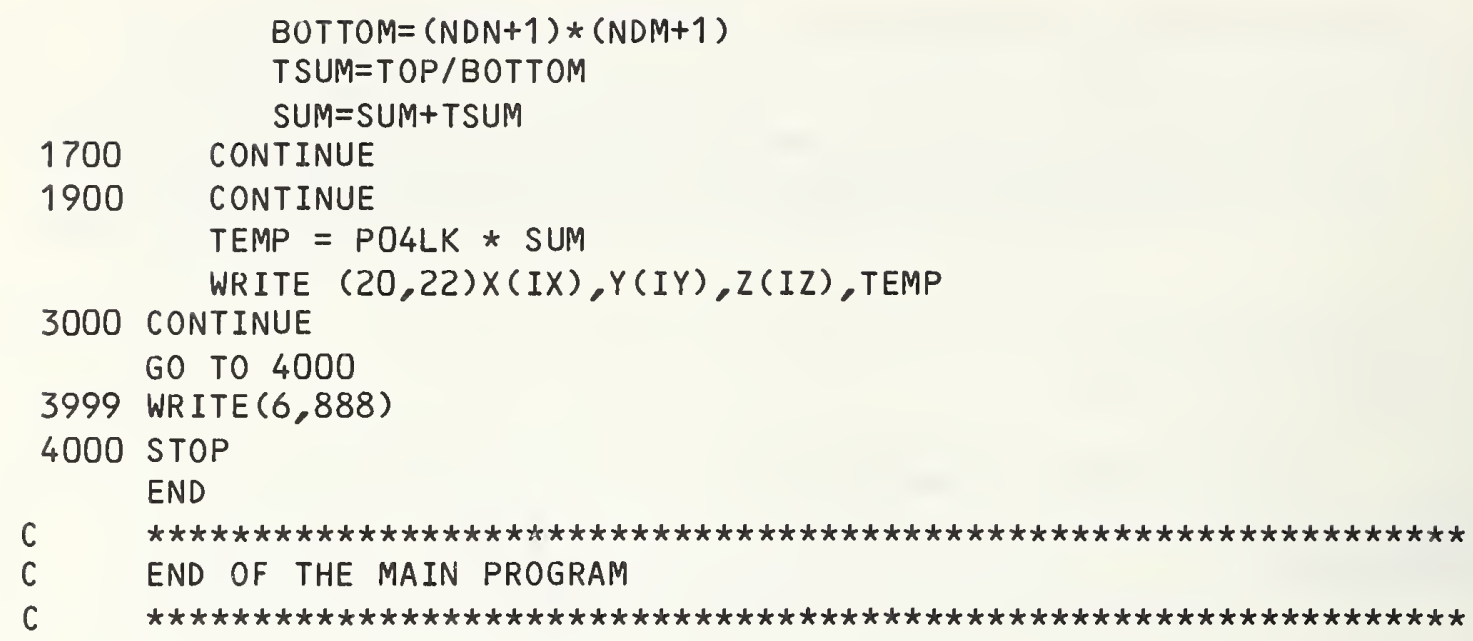


FUNCTION UZERO LISTING

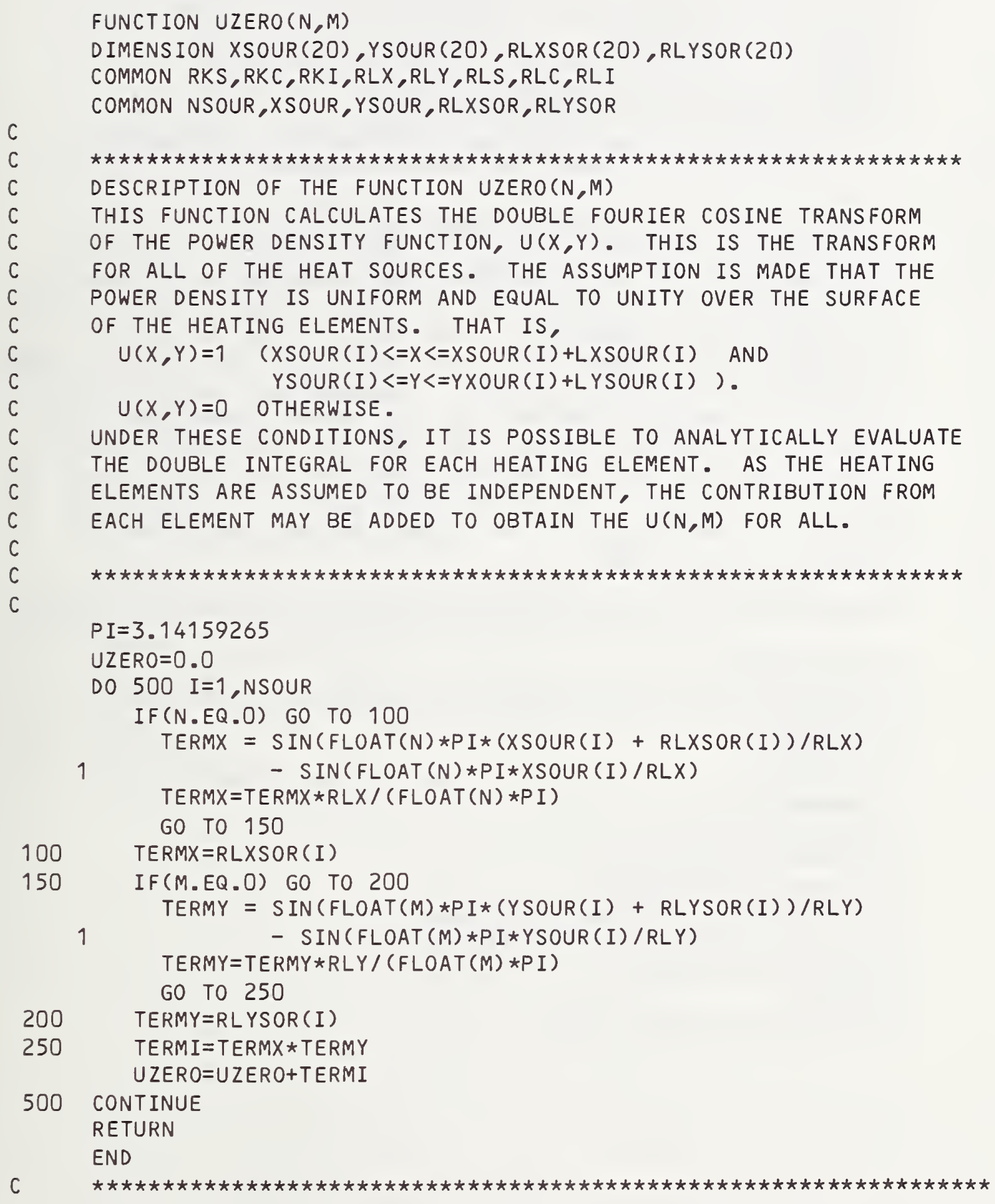


FUNCTION FUNZ $(N, M, Z)$

DIMENS ION XSOUR (20), YSOUR (20), RLXSOR(20), RLYSOR (20)

COMMON RKS, RKC, RKI, RLX, RLY, RLS, RLC, RLI

COMMON NSOUR, XSOUR, YSOUR, RLXSOR, RLYSOR

C

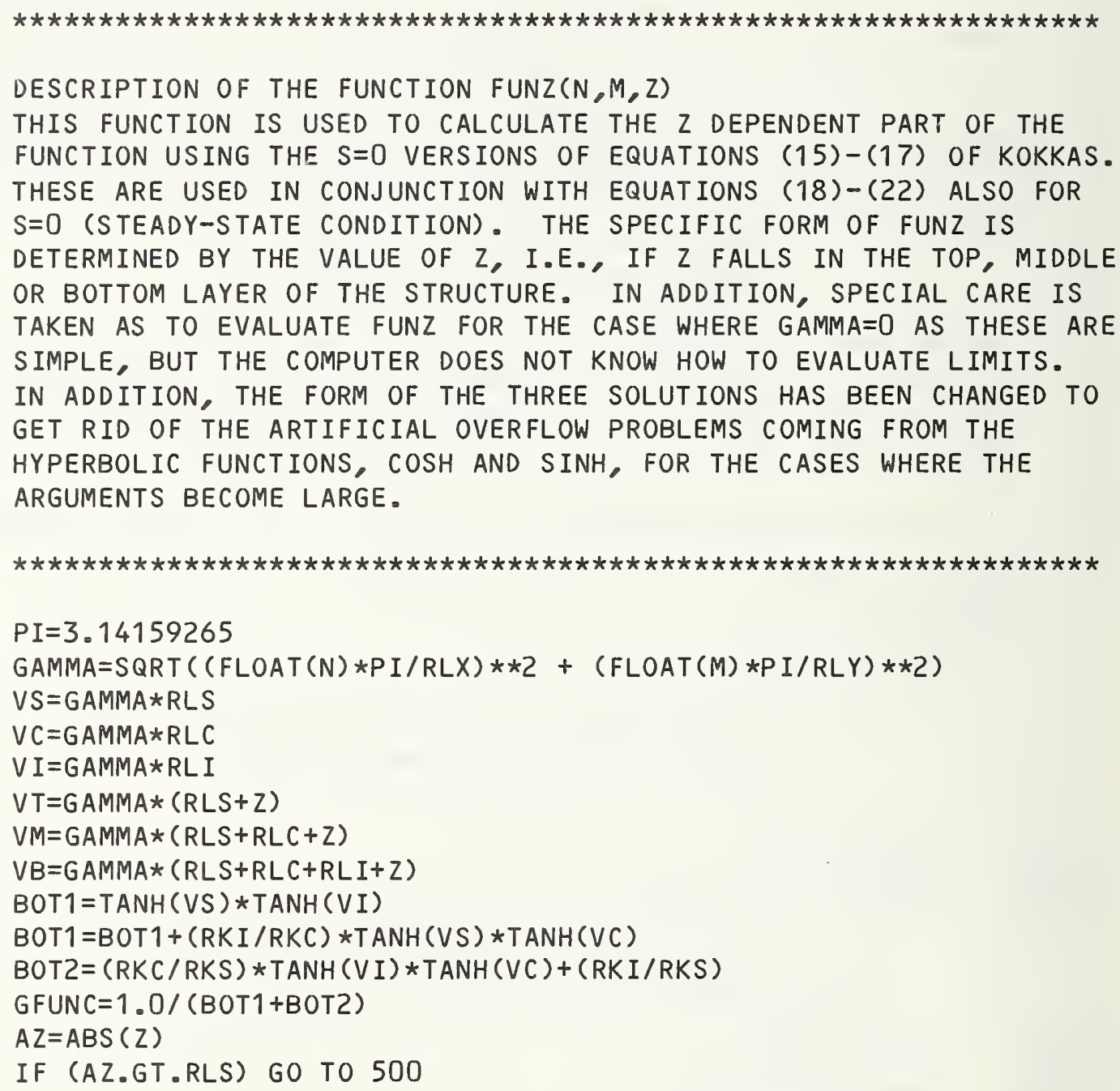




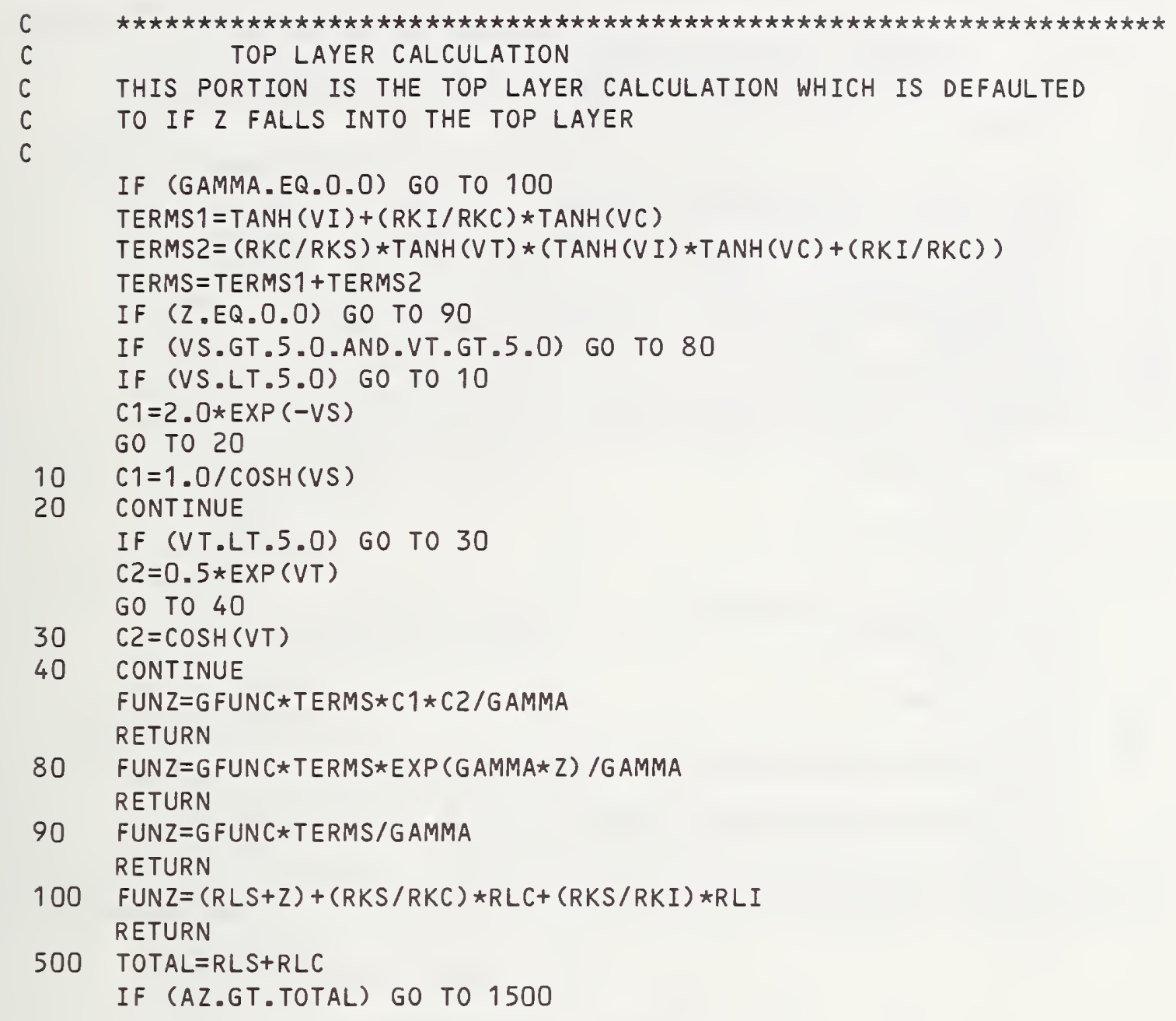




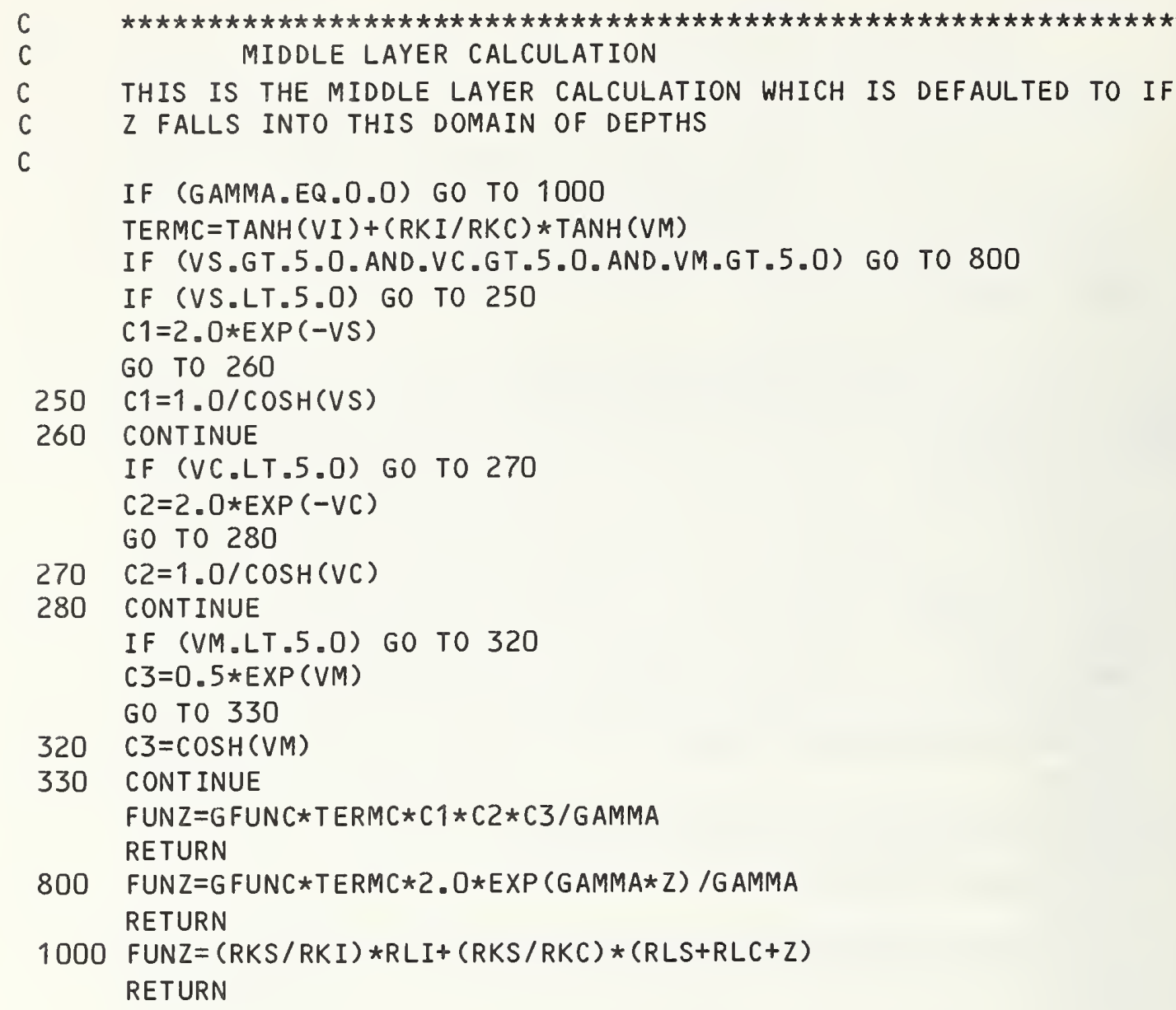


C

C

C

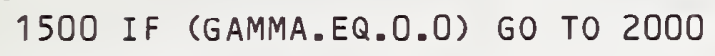


NBS-114A (REV. 2-BC)

\begin{tabular}{|c|c|c|c|c|}
\hline U.S. DEPT. OF COMM. & 1. PUBLICATION OR & 2. Performing Organ. Report Nof 3. Publication Date \\
BIBLIOGRAPHIC DATA & $\begin{array}{c}\text { REPORT NO. } \\
\text { NHES (See instructions) }\end{array}$ & SP 400-76 & & April 1984 \\
\hline
\end{tabular}

4. TITLE AND SUBTITLE

Semiconductor Measurement Technology: TXYZ: A Program for Semiconductor IC

Thermal Analysis

5. $\operatorname{AUTHOR}(S)$

J. Albers

6. PERFORMING ORGANIZATION (If joint or other than NBS, see instructions)

7. ContracuGrant No.

NATIONAL BUREAU OF STANDARDS

DEPARTMENT OF COMMERCE

WASHINGTON, D.C. 20234

9. SPONSORING ORGANIZATION NAME AND COMPLETE ADDRESS (Street, City. State, ZIP)

8. Type of Report \& Period Covered

Final

\section{Same as item 6.}

10. SUPPLEMENTARY NOTES

\section{Library of Congress Catalog Card Number: 84-601026}

Document describes a computer program; SF-185, FIPS Software Summary, is attached.

11. ABSTRACT (A 200-word or less foctuol summory of most significont information. If document includes o significant bibliogrophy or literature survey, mention it here)

A computer program, TXYZ, for the thermal analysis of semiconductor integrated circuits is presented and its applications are discussed. The program makes use of the closed form, analytic solution of the steady-state heat flow problem for a rectangular three-layer structure with multiple heat sources on the top layer. The temperature may be obtained for any point or set of points in the structure and is useful in the determination of the steady-state thermal response of IC chips and packages.

12. KEY WORDS (Six to twelve entries; alphabetical order; capitalize only proper names; and separate key words by semicolons) FORTRAN; Fourier analysis; integrated circuit; semiconductor; steady-state heat flow; thermal analysis; thermal resistance.

13. AVAILABILITY

X] Unlimited

$\square$ For Official Distribution. Do Not Release to NTIS

[x] Order From Superintendent of Documents, U.S. Government Printing Office, Washington. D.C. 20402.

[ Order From National Technical Information Service (NTIS), Springfield, VA. 22161
14. NO. OF PRINTED PAGES 65

15. Price 


\section{Announcement of Semiconductor Measurement Technology List of Publications 72 - 1962-1982}

Semiconductor Materials and Processes Division

National Bureau of Standards

Bldg. 225, Room A 305

Washington, DC 20234

Please send a copy of your latest "Semiconductor Measurement Technology, List - of Publications 72."

Name

Company

Address

City

State

Zip Code 



\section{NBS TECHNICAL PUBLICATIONS}

\section{PERIODICALS}

JOURNAL OF RESEARCH-The Journal of Research of the National Bureau of Standards reports NBS research and development in those disciplines of the physical and engineering sciences in which the Bureau is active. These include physics, chemistry, engineering. mathematics, and computer sciences. Papers cover a broad range of subjects, with major emphasis on measurement methodology and the basic technology underlying standardization Also included from time to time are survey articles on topics closely related to the Bureau's technical and scientific programs As a special service to subscribers each issue contains complete citations 10 all recent Bureau publications in both NBS and nonNBS media. Issued six times a year. Annual subscription: domestic \$18; foreign \$22.50. Single copy, \$5.50 domestic; $\$ 6.90$ foreign.

\section{NONPERIODICALS}

Monographs-Major contributions to the technical literature on various subjects related to the Bureau's scientific and technical activities.

Handbooks-Recommended codes of engineering and industrial practice (including safety codes) developed in cosperation with interested industries, professional organizations, and regulatory bodies.

Special Publications-Include proceedings of conferences sponsored by NBS, NBS annual reports, and other special publications appropriate to this grouping such as wall charts, pocket cards, and bibliographies

Applied Mathematics Series-Mathematical tables, manuals, and studies of special interest to physicists, engineers, chemists, bıologists, mathematıcians. computer programmers, and others engaged in scientific and technical work.

National Standard Reference Data Series-Provides quantitative data on the physical and chemical properties of materials, compiled from the world's literature and critically evaluated. Developed under a worldwide program coordinated by NBS under the authority of the National Standard Data Act (Public Law 90-396).

NOTE: The principal publication outlet for the foregoing data is the Journal of Physical and Chemical Reference Data (JPCRD) published quarterly for NBS by the American Chemical Society (ACS) and the American Insutute of Physics (AIP). Subscriptions, reprints, and supplements available from ACS, 1155 Sixteenth St., NW, Washington, DC 20056
Building Science Series-Disseminates technical irformation developed at the Bureau on building materials, components, systems, and whole structures. The series presents research results, test methods, and performance criteria related to the structural and environmental functions and the durability and safety characteristics of building elements and systems

Technical Notes-Studies or reports which are complete in themselves but restrictive in their treatment of a subject. Analogous to monographs but not so comprehensive in scope or definitive in treatment of the subject area. Often serve as a vehicle for final reports of work performed at NBS under the sponsorship of other government agencies.

Voluntary Product Standards-Developed under procedures published by the Department of Commerce in Part 10. Title 15, of the Code of Federal Regulations. The standards establish nationally recognized requirements for products, and provide all concerned interests with a basis for common understanding of the characteristics of the products. NBS administers this program as a supplement to the activities of the private sector standardizing organizations.

Consumer Information Series-Practical information, based on NBS research and experience, covering areas of interest to the consumer. Easily understandable language and illustrations provide useful background knowledge for shopping in today's technologicál marketplace.

Order the above NBS publications from: Superintendent of Documents. Government Printing Office. Washington. DC 20402.

Order the following NBS publications-FIPS and NBSIR's-from the National Technical Information Service, Springfield, VA 22161.

Federal Information Processing Standards Publications (FIPS PUB)-Publications in this series collectively constitute the Federal Information Processing Standards Register. The Register serves as the official source of information in the Federal Government regarding standards issued by NBS pursuant to the Federal Property and Administrative Services Act of 1949 as amended. Public Law 89-306 (79 Stat. 1127), and as implemented by Executive Order 11717 (38 FR 12315, dated May II, 1973) and Part 6 of Title 15 CFR (Code of Federal Regulations).

NBS Interagency Reports (NBSIR) - A special series of interim or Final reports on work performed by NBS for outside sponsors (both government and non-government). In general, initial distribution is handled by the sponsor: public distribution is by the National Technical Information Service, Springfield, VA 22161, in paper copy or microfiche form 
U.S. Department of Commerce

National Bureau of Standards

Washington, D.C. 20234

Offıcial Business

Penalty for Private Use $\$ 300$ 